\title{
A TRANSLUCENT HONEYCOMB SOLAR COLLECTOR AND THERMAL STORAGE MODULE FOR BUILDING FAÇADES
}

\author{
PETER W. EGOLF ${ }^{1}$, NICOLAS AMACKER ${ }^{2}$, GREGORY GOTTSCHALK $^{3}$, \\ GILLES COURRET ${ }^{4}$, ARSENE NOUME $^{5}$, KOLUMBAN HUTTER $^{6}$
}

\author{
${ }^{1}$ University of Applied Sciences of Western Switzerland, Institute of Thermal Sciences and \\ Engineering, CH 1401 Yverdon-les-Bains, Switzerland, Peter.egolf@ heig-vd.ch \\ ${ }^{2}$ Amstein und Walthert SA, Andreasstrasse 11, 8050 Zürich, Switzerland, nicolasamacker@gmail.com \\ ${ }^{3}$ IQAir AG, Blumenfeldstrasse 10, CH-9403 Goldach, Switzerland, g.gottschalk@bluewin.ch \\ ${ }^{4}$ University of Applied Sciences of Western Switzerland, Institute of Micro and Nanotechnology, \\ CH 1401 Yverdon-les-Bains, Switzerland, Gilles.courret@heig-vd.ch \\ ${ }^{5} 2$ Route de Brumath, 67800 Bischheim, France, arsene.noume@gmail.com \\ 6 \% Laboratory of Hydraulics, Hydrology and Glaciology,
} Swiss Federal Institute of Technology, ETH, CH-8093 Zurich, Switzerland, hutter@vaw.baug.ethz.ch

\begin{abstract}
An innovative new translucent honeycomb solar collector and thermal energy storage module has been designed. The honeycomb module contains two different kinds of channels, namely

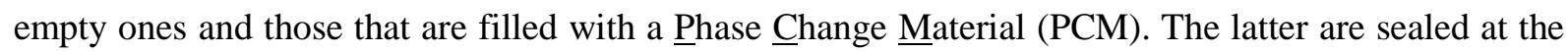
front and back side and, therefore, form chambers. Solar radiation enters the empty channels and is transmitted forward into them. The absorbed energy fraction at the side walls of these empty chambers leads to a melting of the PCM in their neighboring filled chambers, where then thermal energy is stored as latent heat. A heat transfer fluid, usually air, crosses the empty channels by forced convection and additionally charges or discharges the storage modules. Such elements are ideal to equip "intelligent" building façades in passive houses or then to form thermal storage elements in decentralized air-conditioning systems by integration into the façade of e.g. an office building. The article presents the new system and gives results on simplified two-dimensional spatial physical modeling, numerical simulation of charging and discharging modes and of a combined mode. Further work on full system performance, including the description of thermal behavior of buildings, is proposed for future work.
\end{abstract}

\section{INTRODUCTION}

Phase change materials (PCM's), with their combined sensitive and latent heat storage, are useful to increase thermal storage capacities of storage tanks, parts of building constructions, etc. (see pioneering work by Telkes, 1949, by Lane, 1983 and Mehling and Cabeza, 2008 , etc.). Such thermal systems also include cooling applications (see e.g. Haussmann and Schossig, 2006). The use of PCMs has not only a positive effect on the economy of the energy used in buildings, but also on the thermal comfort by a smoothening and damping effect of daily temperature oscillations. This phenomenon is called peak shaving, and its economic feasibility was, for example, demonstrated in Annex 17 of the International Energy Agency (IEA) (see Hauer et al., 2005). This phenomenon is also described in some detail in other ex- 
tensive review articles on the PCM technology for buildings with their passive, active and hybrid systems (e.g. Sharma and Sagara, 2005; Zhang et al., 2007; Kenisarin and Mahkamov, 2007; Zhu et al., 2009; Kuznik et al., 2011; Bouhssine et al., 2016). However, it must be remarked that a slightly varying temperature is advantageous for a good human comfort (Fanger, 2007). By taking this aspect into consideration, the advantage of improved comfort remains, because in our work one is speaking only of reducing too large amplitudes of daily temperature swings, especially in summer time.

The productively available volume that is saved by an application of PCM is very often an economic factor of importance, especially in buildings. Often downsizing of Heating, Ventilation, Air-Conditioning and Refrigeration (HVAC\&R) systems are made possible by an application of PCM building elements, as e.g. gypsum wall boards with incorporated PCMs (see e.g. Haussmann and Schossig, 2006) or microencapsulated PCMs in concrete walls (Cabeza et al, 2007). In a study by Takeda et al., 2003, PCM was applied in a floor supply air conditioning system in granular form. Butala and Stritih, 2006, studied cold storage for building ventilation. Lehmann et al. (2005) propose thermally activated building elements (TABS), which contain PCM in ceilings. Pure PCMs, by their discontinuous (first-order) phase transitions, stabilize temperatures at the melting/freezing point or in mixtures, with continuous (second order) phase transitions, make temperatures to be with higher probability in smaller intervals around the mean melting temperature (see e.g. Egolf and Manz, 1994). These authors have invented a melting/freezing model, which they call the Continuous-Properties Model (CPM). Their theoretical approach - also applied for the modeling and numerical simulation in the present article - has great advantages concerning numerical stability and demanded central processing unit (CPU) time of computers. It has led to numerous practical applications in diverse areas, as the chocolate industry, melting of glaziers, simulation of nuclear reactor melting, etc., but also in buildings, for example by Feustel and Stetiu (1997), who introduced a modified enthalpy function into the basic model of Egolf and Manz.

Some applications pertain to storage vessels with PCMs that are directly penetrated by a heat transfer fluid (see e.g. Egolf et al., 1994, 1997a, 1997b and Martin et al., 2010). The direct contact leads to a high heat transfer efficiency. On the other hand, the PCM must be ideally repelling the heat transfer fluid to guarantee a system that shows a sufficient reproducibility (cyclic stability). Therefore, one usually finds PCMs more frequently in plate-like, spherical or cylindrical encapsulations mounted into a storage vessel. Numerous works have been published on thermal and cyclic stability on nano-, micro- and macro-encapsulated PCMs (see e.g. Zhang et al., 2007; Cabeza et al., 2007; Sinha Ray et al., 2011; Wang et al., 2015). Today, such classical systems can be physically modeled with great success, even if approximate approaches, as e.g. for the free convection of the liquid PCM in the capsules or of the water surrounding the nodules are taken into consideration (Egolf et al., 1997a,b). In experiments Egolf et al., 1994 have also visualized the temperature profiles in PCMs containing nodules of a storage tank with water showing the melting and freezing phenomena. The encapsulation must guarantee a perfect separation of the heat transfer liquid from the solid or liquid phase of the phase change material occupying the inner part of the PCM containers. 
A fine dispersion of PCMs in a carrier fluid leads to a phase change slurry (PCS), a term created at the beginning of the 1990s by the first author of this article. This designation is today also used in a modified manner, namely as phase change material slurry (PCMS). Above a critical particle concentration such a fluid is usually characterized as a Non-Newtonian fluid. Such fluids can be applied, for example, in district heating or cooling systems (see e.g. He et al., 1999). The simplest and unproblematic slurries are ice slurries containing an additive (e.g alcohol or glycol) and water/ice (Egolf and Kauffeld, 2005; Kauffeld et al., 2005; Liu et al., 2015). The small ice particles, of approximately $200 \mu \mathrm{m}$ typical extent, allow a pumping of the ice slurry, which conceptually is treated as a Bingham substance. Heinz and Streicher (2005) tested micro-encapsulated PCS filled into a storage tank. For renovations or expansions of district heating or cooling systems, the higher enthalpy density of the PCS compared to a conventional brine, to obtain a higher transport power, can avoid the necessity of building a new piping system with larger diameters. Similar fluids, as e.g. micro-emulsion slurries, are an alternative to ice slurries and were investigated e.g. by Hadjieva et al., 2003, who also studied their structural stability and the thermal energy storage capacity. Such fluids are mainly used as secondary refrigerants in large refrigeration systems.

Besides these classical applications, there were always attempts to also create new innovative systems by an application of PCMs. With the utilization of solar energy in mind, transparent or at least translucent building elements with the properties of day lighting and thermal energy storage were developed (see Wong et al., 2007, Kudhair and Farid, 2004, Grynning, et al., 2013). Especially salt hydrates, containing water, have the property not to absorb visible light so much. Therefore, they are ideal as PCMs that can be used in a two-fold manner: The visible diffuse light is transmitted, which is ideal for studios, libraries, etc. and the ultraviolet and the infrared parts of the light spectrum are absorbed and lead to a desired melting of the PCM for thermal energy storage. Because such elements are utilizing solar energy in a direct application, they are usually located in the building envelopes and, therefore, must obey some requirements suppressing fire propagation. Viewed from this aspect, salt hydrates are more ideal than organic groups of materials, as e.g. fatty acids or paraffins. Such a system was, for instance, developed by Manz et al., 1997. These authors have not only scientifically investigated their system by applying to their processes the Monte Carlo simulation method and using experimental work; an architect, in contact with these scientists, has also initiated some industrial production and practical building applications (see e.g. Schwarz and Nussbaumer, 2002). Some years later, it was shown that such a system can also perform well by simply replacing the transparent insulation by a conventional glazing (see Weinläder et al., 2005). Balocco et al. (2001) studied the behavior of different transparent glass and plastic sheets and films. Wong et al. (2007) performed an extensive review on transparent insulations (TI). Platzer (1987) worked on the solar transmission of transparent insulation; moreover, it was also Platzer (1992) who investigated the directional hemispherical solar transmittance in plastic honeycomb-type structures. Finally, Ismail et al. (2008) performed a comparison between glass windows, filled with an absorbing gas, and transparent insulations, respectively.

In the following article, a new innovative building element - also translucent - is presented. It consists of a honeycomb structure with longitudinal chambers. Some of these chambers are filled with a PCM, to a degree of e.g. $90 \%$, to counterbalance volume changes between 
the solid and liquid phase. On the other hand, the empty chambers, in the front and at the back, open to the free atmosphere or covered by a glass, respectively, lead to the advantage that the storage module, by forward transmission of direct and diffuse solar radiation, can be easily charged also at deeper locations in the module. The absorption property of the inner surface of the empty channels have a finely tuned absorption coefficient given by special material coatings. This module is described in more detail in the next section. The article describes first basic investigations by physical modeling and numerical simulations of such PCM modules. The basic physical modeling and simulation work with Matlab tools was performed by Amacker (2011). In a Master thesis (Noume, 2010) possible applications in decentralized solar air-conditioning systems were evaluated by even taking, in a more extended and expensive system, the future-oriented magnetic heating and cooling technology into account (see e.g. Auracher and Egolf, 2006; Egolf and Rosensweig, 2007). This work was further presented by Egolf et al., 2014 to politicians and stakeholders in an International Special Issue of the United Nations Environmental Program, UNEP and in an Italian industrial formation journal (see Egolf et al., 2015). A number of such and similar modules is foreseen to be designed and technically realized in the foreseeable future.

\section{THE NEW STORAGE MODULE}

In certain applications, the PCM is simply filled into a tank. However, more frequently the PCM is encapsulated in plastic containers of plate-like, cylindrical or spherical shape (see Section 1). The encapsulation in glass blocks or transparent small plastic containers or capsules, respectively, widens the spectrum to applications with direct light utilization.
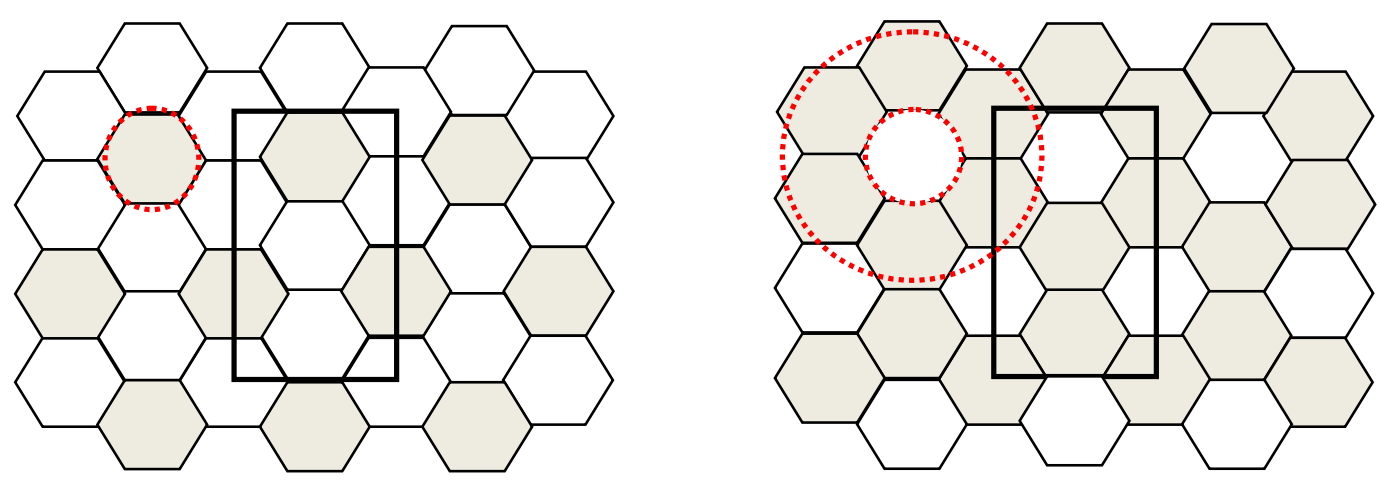

Fig. 1. In this figure two Honeycomb-PCM (HPCM) storage modules of hexagon type are shown. The one on the left-hand side shows a filling degree of $33.3 \%$ and that on the righthand side a higher one of $66.6 \%$. The rectangles present periodically repeatable domains that allow easy package degree calculations. 
These panels show the honeycomb structures as being built perpendicular to the building façade. In the physical modeling in this article regular polygons are approximated by circular geometries (dotted red circles). The higher the order of the polygon (number of kinks) is, the better this approximation applies. The main objective of this and further approximations is to keep the problem azimuthally symmetric, and by this to obtain a low dimensionality, in our case to restrict ourselves to a three dimensional problem, by introducing only a time and two space coordinates (see below).

In the new module, the transparency, allowing direct solar light absorption, is combined with some excellent heat transfer characteristics. This is obtained by filling certain chambers of a transparent honey comb structure at a high package degree, with a PCM and then by sealing them, whereas neighboring chambers are left open and empty (see FIG. 1). In the empty channels, solar light can enter by forward transmission or/and heat can be transferred via convective transport by a fluid into or out of the storage elements.

There are numerous honeycombs with different capillary tubes, polygon-shaped channels, produced with inorganic or organic materials, as e.g. glass, polycarbonate (PC), etc., including also channels of triangular, rectangular or higher-order polygonal shapes.

The filling degree of such a structure is determined by figuring out a domain which is then periodically continued. In FIG. 1 areas of empty (white colored) and filled chambers (gray colored) are shown for two different structures. Then the filled areas in such a domain are calculated and put into relation to its total area, which then leads to the areal and by multiplying with the depth of the honeycomb structure to the volumetric package degree.

The building of such structures must be executed to achieve highest mechanical stability. Furthermore, the industrial filling of the chambers with PCM and the sealing of the chambers must be efficiently and economically realized. Up-to-present these two more practical aspects have not yet been studied.

\section{PHYSICAL MODELING}

\subsection{Absorption of direct solar radiation}

The honeycomb storage module, with its empty and filled channels as shown in FIG. 2 , absorbs solar radiation. In this figure only the ray tilted by the angle $\theta$ that enters the honeycomb in the center cut through the module is shown. Parallel rays to the ray lying in this center plane act differently and this will be discussed below. The empty channels reflect the light forward into the body of the element and with each encounter of the occurring multireflection process some energy is absorbed by the neighboring filled channels. For a single solar ray, the absorption at different locations is a discrete process in space. The filled chambers absorb the arriving energy flux fully at their front side. This is shown in FIG. 2 on the left- 


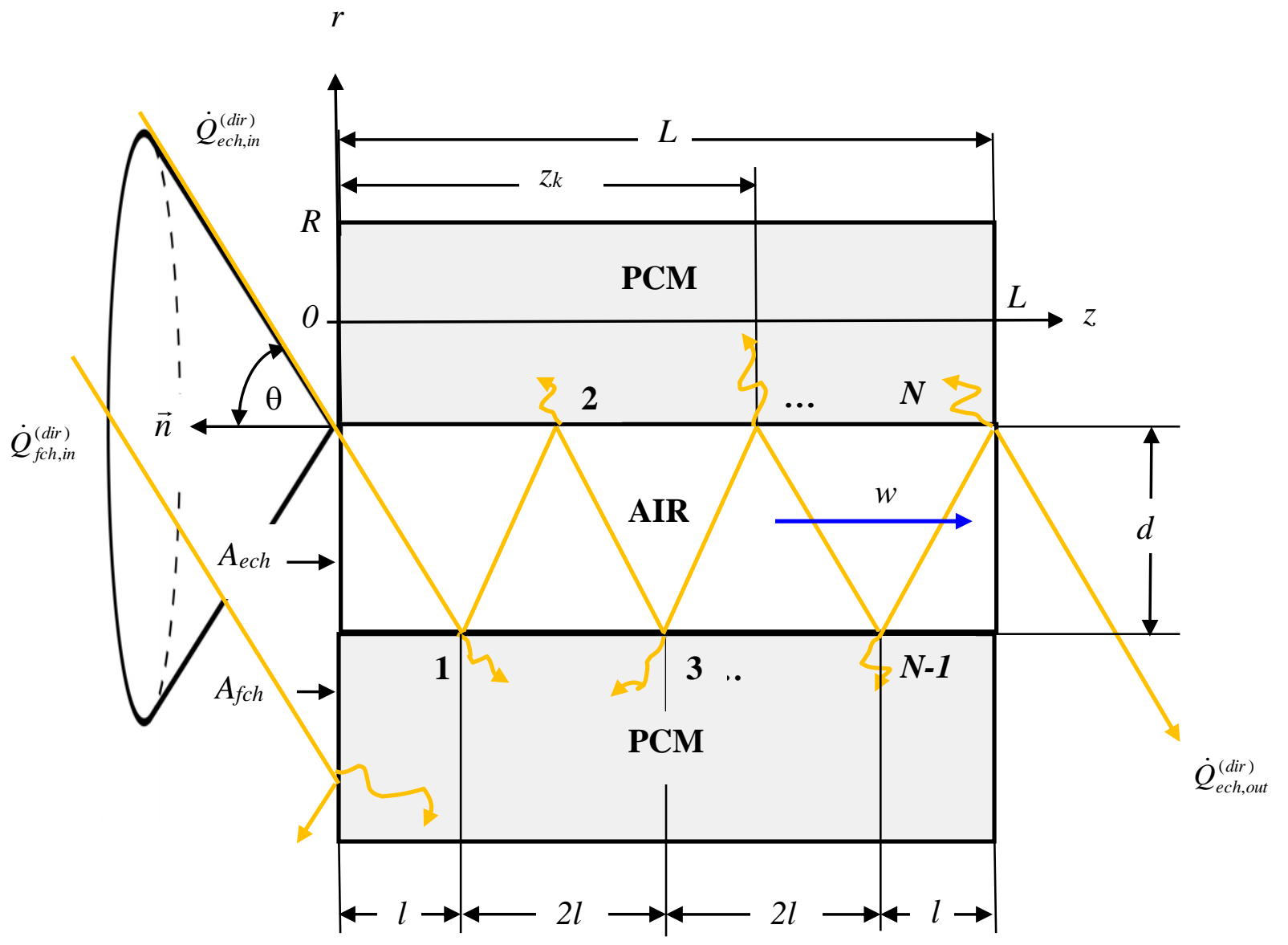

Fig. 2. The absorption phenomenon occurring in the vertical center plane or a cut through a honeycomb storage module. There are two types of elements; a first type of channel is empty and a second type filled with a PCM (see (two) gray underlain channels). The empty channels permit radiation to enter deep into the body of the module.

hand side. Of advantage is that for the first case an effective absorption coefficient can be derived.

An incoming ray of solar radiation, tilted by the angle $\theta$ with respect to the normal vector of the building façade module, $\vec{n}$, is shown in FIG. 2 on the left-hand side. Notice that all situations with a ray of angle $\theta$ are laying on a conus with its tip at the façade and its axis laying on the same line as the normal vector of the façade. Because our modeling shall be reduced to a simplified azimuthal situation the cone may always be turned around its axis till the ray lies in the vertical plane as shown in the figure, without changing the physical relevant results of absorption at the cell walls and diffusion in the cells containing phase change material.

If the direct solar radiation has an intensity $I$, then the heat flux entering an empty channel (denoted by the subscript ech) is

$\dot{Q}_{e c h, i n}^{(\text {dir })}=\dot{Q}_{e c h, 0}^{(d i r)}=A_{e c h} I \cos \theta$

in which $A_{e c h}$ is the (fractional) surface of the empty channels of the façade. 
The uniquely reflected solar ray leads to the energy flux

$\dot{Q}_{e c h, 1}^{(d i r)}=r_{s}^{(\chi)} \dot{Q}_{e c h, 0}^{(d i r)}$,

with two surface coefficients of reflection $r_{s}^{(\chi)}$, obeying the laws

$r_{s}^{(\chi)}=1-a_{s}^{(\chi)}, \quad 0 \leq a_{s}^{(\chi)}, r_{s}^{(\chi)} \leq 1, \quad \chi \in\{$ dir, dif $\}$,

where $a_{s}^{(\chi)}$ denotes the dimensionless surface coefficients of absorption. Moreover, the superscripts 'dir' and 'dif' denote direct and diffuse radiation, respectively. The subscripts ' 0 ' and ' 1 ' denote the incoming and only once reflected energy fluxes given by the solar rays.

This process goes on, and by recurrence for position $k$, one finds

$\dot{Q}_{e c h, k}^{(d i r)}=r_{s}^{(d i r)} \dot{Q}_{e c h, k-1}^{(d i r)}=r_{s}^{(d i r)^{k}} \dot{Q}_{e c h, 0}^{(d i r)}$

From FIG. 2, one may read off the geometrical relation for the number of encounters of the solar rays onto the walls of surrounding channels for the rays

$k=\operatorname{int}\left(\frac{z_{k}}{l}\right)$

where a multitude of reflections is assumed to occur and int (...) denotes the nearest integer to the argument, smaller than this argument. In a simplification, this command is dropped again when the model will be transformed from the discrete to its continuous version (see below).

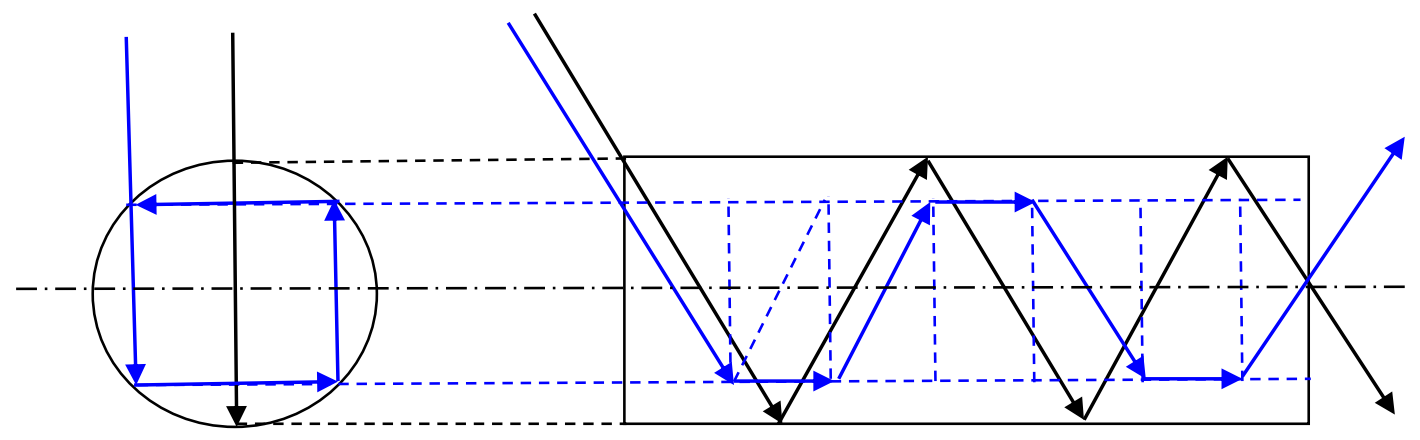

FIG. 3. Two types of rays are shown, a first in the center plane (black color) and a second one parallel to it (blue color). Rays not in the center plane rotate in the pipe. In the projection on the left the periodic cases lead to polygons; in the presented case it shows four kinks and, thereby, leads to a "square-type" absorption process. The occurring possible reflection processes are shown in FIG. 4. 

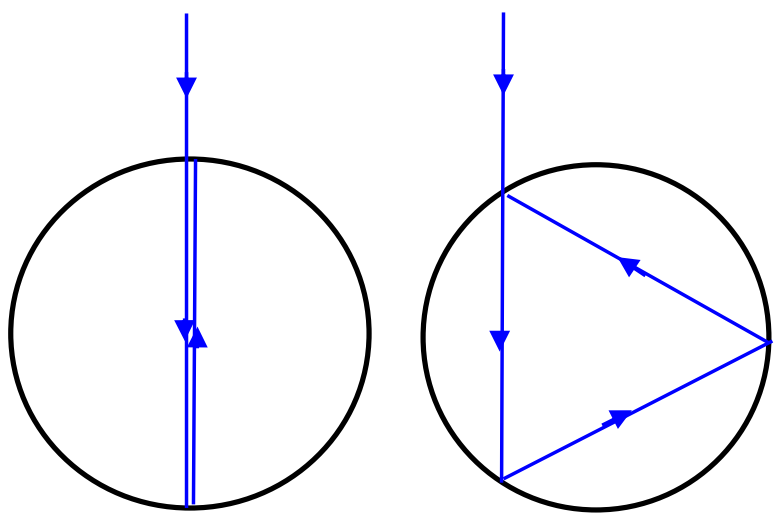

$n_{r}=1, n_{k}=2$

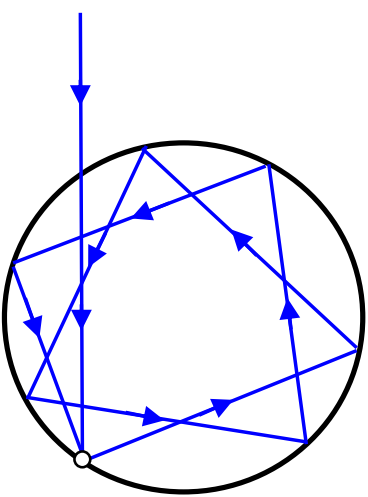

$n_{r}=2, n_{k}=4$

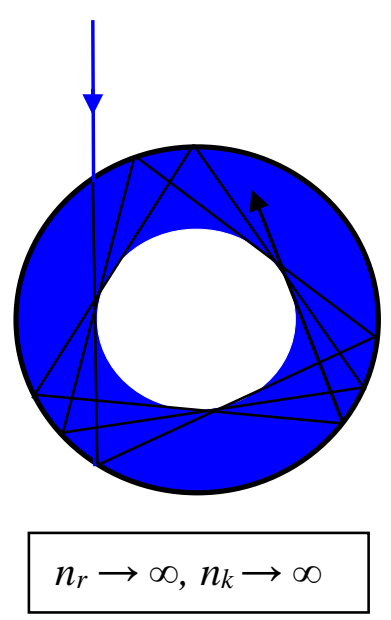

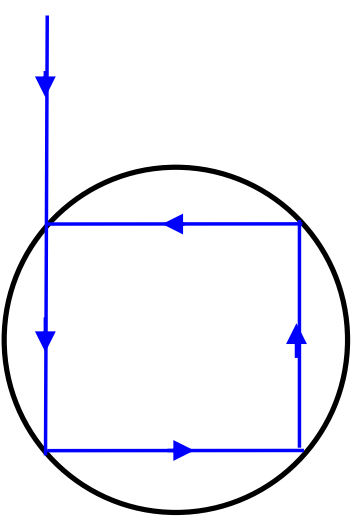

$n_{r}=1, n_{k}=4$

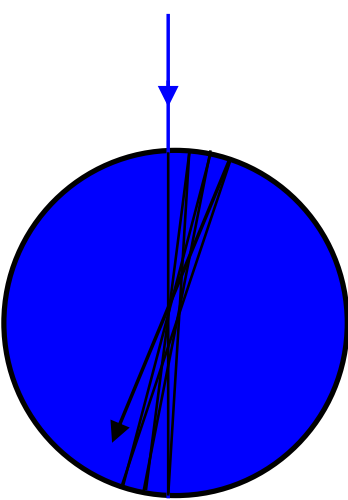

$n_{r} \rightarrow \infty, n_{k} \rightarrow \infty$

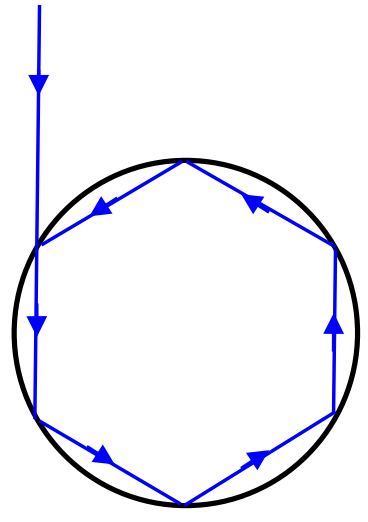

$n_{r}=1, n_{k}=6$

FIG. 4. Type 1 reflections with rotation number $n_{r}=1$, leading to polygons with $n_{k}=2,3,4$ and 6 kinks are shown in the first line from left to right. A type 2 periodic solution with rotation number $n_{r}=2$, showing a closing after two rotations (small circle) and $n_{k}=8$ kinks is presented in the bottom line on the left. All these cases are commensurable processes. However, type 3 reflections are shown in the last two figures, which represent the incommensurable cases, where the rays densely cover areas and there is no repetition in the to the front projected absorption locations. In these last cases only a first few rays are drawn.

First, the simple situation in the center plane of FIG. 2 is made visible in FIG. 3 with black colored rays in a projection toward the façade and a vertical cut through a cell. On the right-hand side the identical situation as in FIG. 2 is observed.

However, there are other rays, which occur in vertical planes parallel to the vertical center plane, as e.g. the blue ray shown in FIG. 3. These rays show steps between absorption processes (points where the ray hits the cell wall) which occur at different azimuthal angles. The occurring configurations can be assumed to be like discretizised rotational geometrical configurations. The farther the vertical plane containing the ray is from the center plane, the smaller the steps will be. 
We distinguish three types of rotations (see FIG. 4). Type 1, is characterized by absorption processes which, in a projection of the front, close a reflection sequence on the circle after a single rotation of $2 \pi$. The first row in this figure shows situations in which, after a single rotation of $2 \pi\left(n_{r}=1\right)$, a ray track produces a polygon with $n_{k}=2,3,4,6 \ldots$ ray segments. Type 2 also shows a closed rotation, but the closure only arises after more than a single rotation as sketched in the lower line on the left-hand side. The ray segments from the first vertical entry of the light ray reaches a reflection point of previous ray segments. These first two cases are called commensurable cases: the ray sequences are periodic. Type 3 is the incommensurable case where no such closing after a finite number of reflections occurs; the reflection points on the circle are therefore densely distributed around the circle. Equally, the ray segments completely fill the interior of a concentric ring (figure in the middle) or even of the entire circle (figure on the right). This is sketched by a complete filling these interior domains by a continuous blue shading. No closing occurs and the rays hit always different azimuthal locations and cover densely all the azimuthal angles between 0 and $2 \pi$.

Finally, we notice that $l$ (in FIG. 1) is a function of the location of the vertical plane, where the corresponding rays are embedded. For example, in FIG. 3 it is evident that this length is a maximum in the center plane and is smaller the farther the plane is located from the center, becoming zero at the circle's periphery. To study this situation please consider FIG. 5.

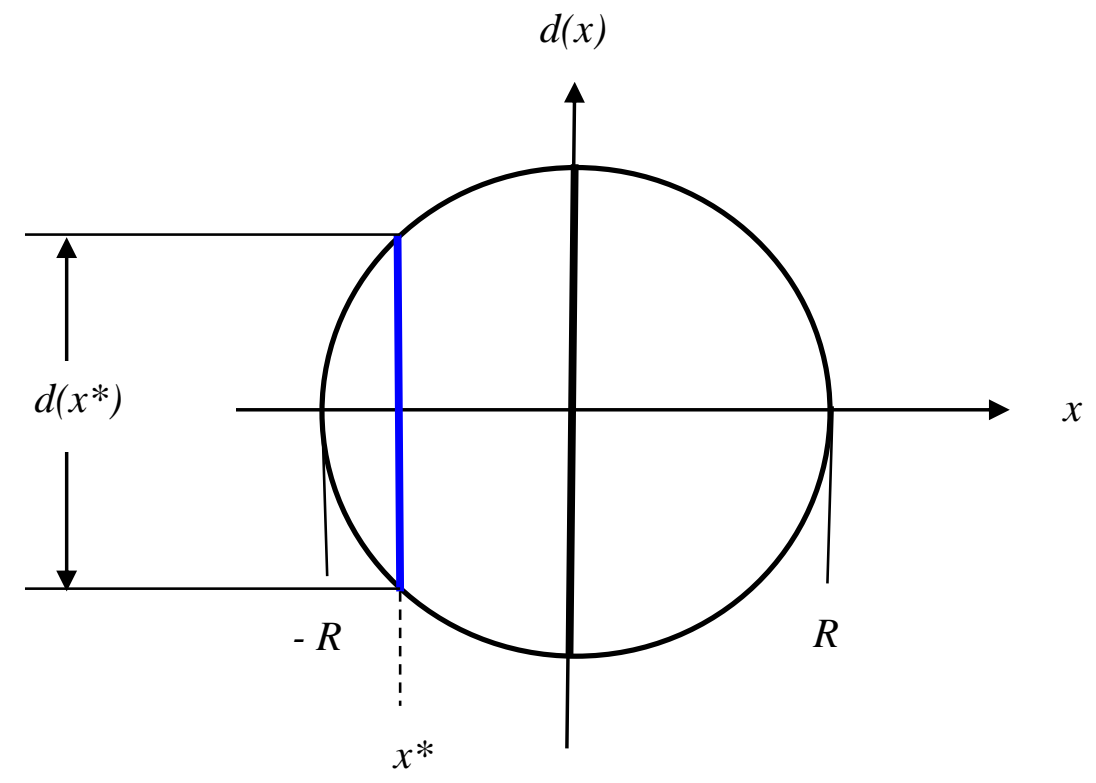

FIG. 5. The corrected diameter as a function of the location of the vertical plane. At $x^{*}=0$ it corresponds to the diameter of a cellular chamber $d=d(0)$ and decreases toward both sides to yield $d(-R)=d(R)=0$. The portion of rays occurring in a vertical plane is proportional to this variable distance $d(x)$ and is an important measure to define a probability distribution (see text). 
The simplifying idea of our model is to work with a weighted (mean) step size $\bar{l}$ for the absorption processes. It is clear that this is a crude approximation of a highly complex geometrical situation where billions of photons enter the channel, each having its particular (eventually rotating) path in the cylindrical cell. An accurate description could be obtained by a Monte Carlo simulation, in which a large ensemble of photons is shot into the channel and all the occurring reflections on the channel wall are registered and statistically evaluated. In this manner the azimuthal light energy absorption distribution could be determined. It is assumed that this distribution would slightly peak at the incident angle $\theta$ and its opposite location, which is found at the angle $\theta+\pi$. This peaking is decreasing to the back of an empty channel. In our model this inhomogeneity is neglected and, thereby, an azimuthally symmetric distribution is assumed. However, with the thermal diffusion processes such minor effects are smeared out and will not change the macroscopic energy fluxes perceptibly.

As shown in FIG. 5, one has

$$
d(x)=2 \sqrt{R^{2}-x^{2}}, \quad-R \leq x \leq R .
$$

It is evident that the number of rays from a uniform source entering a channel in a vertical plane located at $x$ is proportional to $d(x)$. The maximum number of photons will arrive in the center plane, whereas at $\pm R$ there are none. Therefore, we can write a probability distribution for arriving photons as a function of $x$

$$
p(x)=\frac{\sqrt{R^{2}-x^{2}}}{\int_{-R}^{R} \sqrt{R^{2}-x^{2}} d x}=\frac{2}{\pi R^{2}} \sqrt{R^{2}-x^{2}},
$$

a distribution that is evidentially normalized, viz.,

$$
\int_{-R}^{R} p(x) d x=1
$$

Now, we can calculate the weighted "diameter" to yield

$$
\bar{d}=\int_{-R}^{R} p(x) d(x) d x,
$$

which is

$$
\bar{d}=\frac{4}{\pi R^{2}} \int_{-R}^{R}\left(R^{2}-x^{2}\right) d x .
$$


The result of the integration yields

$\bar{d}=\frac{4}{\pi R^{2}}\left(\left.R^{2} x\right|_{-R} ^{R}-\left.\frac{1}{3} x^{3}\right|_{-R} ^{R}\right)=\frac{16}{3 \pi} R=\frac{8}{3 \pi} d=0.849 d$

For the central plane case, the length $l$ is expressible by the diameter of an empty channel, $d$ (see FIG. 2)

$l=\tan \left(\frac{\pi}{2}-\theta\right) d=d \cot \theta$

The diameter is now substituted by the weight-averaged diameter. With the help of (3.1/11d) and $(3.1 . / 12 \mathrm{~b})$ this leads directly to the weight-averaged length

$\bar{l}=\bar{d} \cot \theta=\frac{\bar{d}}{d} l=0.849 l$

In analogy to $(3.1 / 5)$, the weight-averaged quantity takes the form

$\bar{k}=\operatorname{int}\left(\frac{z_{k}}{\bar{l}}\right)=\operatorname{int}\left(\frac{z_{k}}{\bar{d}} \frac{1}{\cot \theta}\right)=\operatorname{int}\left(\frac{z_{k}}{\bar{d}} \tan \theta\right)$.

Therefore, one concludes that

$$
N=\operatorname{int}\left(\frac{L}{d} \tan \theta\right), \quad \bar{N}=\operatorname{int}\left(\frac{L}{\bar{d}} \tan \theta\right),
$$

where $N$ is the number of reflections in a chamber of a ray in the central plane and $\bar{N}$ denotes the weight-averaged number of hits of all rays arriving at any location between $x=-R$ and $x=$ $R$.

Let us next substitute Eq. (3.1/14c) into (3.1/4b). Then, we replace $z_{k}$ by $z$ and drop the notation int (...) and obtain

$\dot{Q}_{\text {ech }, k}^{(d i r)}=\dot{Q}_{\text {ech }}^{(d i r)}\left(z_{k}\right) \quad \Rightarrow \quad \dot{Q}_{\text {ech }}^{(d i r)}(z)=r_{s}^{(d i r) \frac{z}{\bar{d}}}{ }^{\tan \theta} \dot{Q}_{\text {ech }}^{(d i r)}(0)$,

which implies

$\log _{e} \dot{Q}_{e c h}^{(d i r)}(z)=\frac{z}{\bar{d}} \tan \theta \log _{e}\left(r_{s}^{(d i r)}\right)+\log _{e} \dot{Q}_{e c h}^{(d i r)}(0)$. 
Taking the exponential function of this expression and substituting Eq. (3.1/1b) leads to

$$
\dot{Q}_{\text {ech }}^{(d i r)}(z)=A_{e c h} I \cos (\theta) \exp \left[\log _{e}\left(r_{s}^{(d i r)}\right) \frac{z}{\bar{d}} \tan \theta\right]
$$

Using product separation, this can equally be written as

$\dot{Q}_{\text {ech }}^{(d i r)}=a_{e c h}^{(d i r)} A_{e c h} I$,

with the global absorption coefficient $a_{e c h}^{(d i r)}$, which is not a physical, but an effective quantity

$$
a_{e c h}^{(d i r)}=\exp \left(-\frac{z}{\zeta_{\text {ech }}^{(d i r)}}\right) \cos (\theta), \quad \zeta_{\text {ech }}^{(d i r)}=-\frac{\bar{d}}{\log _{e}\left(r_{s}^{(d i r)}\right) \tan \theta} .
$$

Virtual averaged rays reflected in an empty channel $\bar{N}$ times and arriving to the right end of the module (see FIG. 2), produce an out-coming energy flow. Therefore, it follows from Eq. (3.1/18) with $z=L$ that

$$
\dot{Q}_{\text {ech,out }}^{(d i r)}=\dot{Q}_{c h}^{(d i r)}(L)=A_{e c h} I \cos (\theta) \exp \left(\log _{e}\left(r_{s}^{(d i r)}\right) \frac{L}{\bar{d}} \tan \theta\right) .
$$

There are numerous special cases, which make the correctness of this formula plausible. If $\theta$ is $90^{\circ}$ no radiation energy enters the device. If $A_{e c h}$ is zero, the same is the case. If the coefficient of reflection is $r_{s}^{(d i r)}=1$, it follows that $\dot{Q}_{\text {ech,out }}^{(d i r)}=\dot{Q}_{\text {ech,in }}^{(d i r)}$, which is correct as it states that no radiation is absorbed. Full absorption is described by $a_{s}^{(d i r)}=1$, and then from Eq. (3.1/3a) it follows that $r_{s}^{(d i r)}=0$ and its logarithm approaches $-\infty$ and its exponential is equal to zero. Therefore, no energy crosses the device. If $\theta=0$ then the radiation crosses the device horizontally and no energy can be absorbed. If $\theta=90^{\circ}$ not only the term in front of the exponential, of (3.1/18), but also the tangent function in the exponent contributes to a vanishing energy flow.

The ratio of the solar radiation crossing the storage device completely, $\dot{Q}_{\text {ech,out }}^{(d i r)}$, to that entering the device, $\dot{Q}_{\text {ech,in }}^{(d i r)}$, is

$$
\Omega=\frac{\dot{Q}_{\text {ech,out }}^{(d i r)}}{\dot{Q}_{\text {ech,in }}^{(d i r)}}=\exp (\chi \tan \theta), \quad \chi=\log _{e}\left(r^{(d i r)}\right) \frac{L}{\bar{d}} \leq 0,
$$

where $\chi$ does not have the same meaning as e.g. in Eqs. (3.1/2) and (3.1/3), where in these equations it is only used as a superscript. 


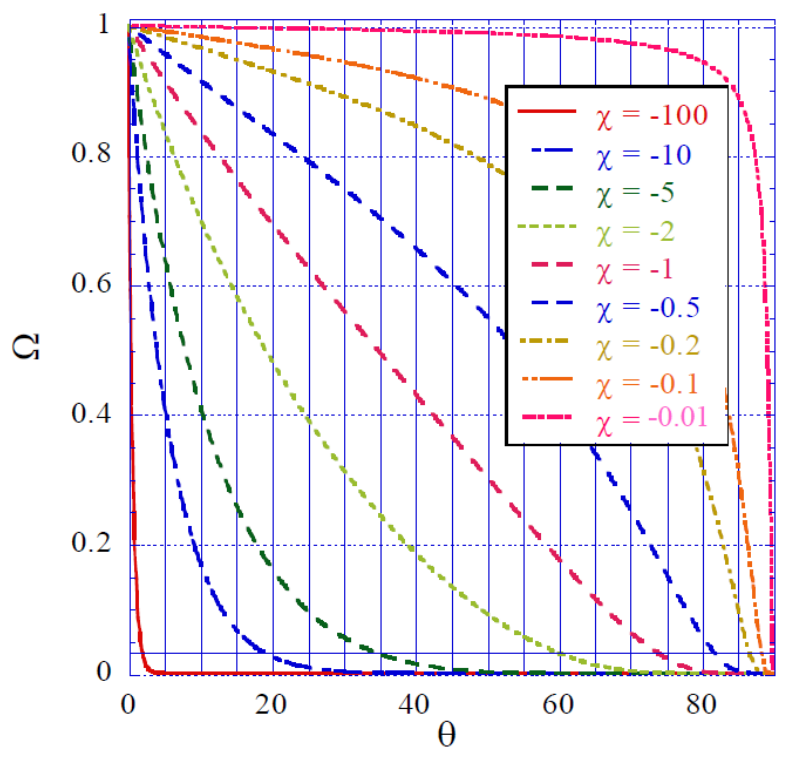

Fig. 6. Comprehensive presentation of the absorption properties of a honeycomb device partly filled with a PCM. This graph presents the ratio of the radiation energy flux entering at the front and leaving the device at the back. This ratio is always positive and smaller or equal to ' 1 '. The remaining energy flux leaving the device at the back depending on the frequency of the emitted light - can be used for day lightening purposes or then for absorption in the back-laying room for heating purposes.

The results of these considerations are shown in FIG. 6, where $\Omega$ is plotted against $\theta$ for different values of $\chi$.

The exponential power reduction, described by Eq. (3.1/22b), is directly connected with the energy flux, which penetrates perpendicular to the façade in the radial direction into the PCM.

In this article, a spatially two-dimensional model is applied. This demands for filled cylindrical cells. If polygon structures are applied, actually a spatial three-dimensional approach is required. In a simplification fictive cylindrical cells, with a volume identical to the volume of a polygon filament and a surface that is identical to the surface of this polygonal element, must be applied. Such approximation techniques are frequently used to simplify engineering problems and, therefore, will not be outlined. A positive argument for this approximation is also that a polygonal overall structure with polygons of order $n_{k}\left(n_{k}=\right.$ number of kinks) with $n_{k}$ toward infinite, converges toward the two-dimensional modeling of geometrically simpler cylinders, which is applied in this article. Further clarifying remarks are given in section 3.5 .

In the following the radial energy flux at the wall of the cylindrical channel with radius $r=R$ shall be modeled. There, one has

$$
d \dot{Q}_{r}^{(d i r)}(R, z)=n \frac{d \dot{Q}_{e c h}^{(d i r)}(z)}{d z} d z=-\frac{n A_{e c h} I \cos (\theta)}{\zeta_{e c h}^{(d i r)}} \exp \left(-\frac{z}{\zeta_{e c h}^{(d i r)}}\right) d z,
$$

where $n$ denotes the ratio of the number of empty channels divided by those filled with a PCM. To determine this, one can study again the framed rectangles in FIG. 1. Then, one finds for the figure on the left the areas of four empty and two full channels. Therefore, four empty channels give their energy flux to two full channels implying $n=2$. In the situation of the panel 
on the right, one finds only the area of two empty channels, against four full ones, implying $n=1 / 2$. With this concept, one may view the network on average as if it would consist of a single full channel. The characteristics of the total storage is then obtained by a parallel network, which corresponds to identical intensive variables of single entities (e.g. the temperatures) and an additivity of extensive variables (e.g. volume, energy, etc.) by the number of full chambers in the honeycomb storage device.

The heat flux in the radial direction is weakened by photon absorption. Introducing a bulk absorption coefficient

$$
a_{b}^{(\chi)}=\frac{1}{\rho^{(\chi)}}, \quad \chi \in\{\text { dir, dif }\}
$$

which is a reciprocal characteristic length, called penetration length $\rho^{(\chi)}$, one can write

$$
d \dot{Q}_{r}^{(d i r)}(r, z)=-\frac{n A_{e c h} I \cos (\theta)}{\zeta_{e c h}^{(d i r)}} \frac{\cosh \left(\frac{r}{\rho^{(d i r)}}\right)}{\cosh \left(\frac{R}{\rho^{(d i r)}}\right)} \exp \left(-\frac{z}{\zeta_{e c h}^{(d i r)}}\right) d z, \quad \rho^{(d i r)}<<D .
$$

The normalized $r$-dependent fractional term is a reasonable approximation to the real problem. In a half-infinite extended domain, the absorption process leads to an exponentially decaying function. In a plate, with entering rays from both surfaces, a superposition of the exponential functions, describing both absorption processes, leads to a hyperbolic cosines dependence as given in our approach. To apply the model of a plate to a cylinder, one requires the condition $\rho^{(d i r)}<<D$, which in our example (see Sect. 4) is numerically fairly well fulfilled (compare with numerical values in Table 1). Furthermore, we see that at the boundary of the cell it follows that $d \dot{Q}_{r}^{(d i r)}(R, z)$ is just identical to the special case $(3.1 / 23 \mathrm{~b})$. Then, one notices that on the cylinder axis the requirement, $d \dot{Q}_{r}^{(d i r)}(0, z) / d r \propto \sinh (0)=0$, is fulfilled, guaranteeing a symmetric profile in the domain $-R \leq x \leq R$, where $x$ is the extended radius also incorporating negative values. All these features provide confidence of the usefulness of approximation (3.1/25).

Now, the radial component of the heat flux density vector can be determined. We state

$\dot{q}_{r}^{(d i r)}(r, z)=\frac{d \dot{Q}_{r}^{(d i r)}(r, z)}{d A_{r}}$,

with the radial area $A_{r}$ depending on the radius $r$,

$d A_{r}=2 \pi r d z$ 
This representation indicates that we now replace the hexagonal form of the PCM structure approximately by the circular cylinders as indicated in FIG. 1.

Substituting Eq. (3.1/25) and (3.1/27) into (3.1/26), the final radial heat flux density takes the form

$$
\dot{q}_{r}^{(d i r)}(r, z)=-\frac{1}{2 \pi} \frac{n A_{e c h} I \cos (\theta)}{\zeta_{e c h}^{(d i r)}} \frac{1}{r} \frac{\cosh \left(\frac{r}{\rho^{(d i r)}}\right)}{\cosh \left(\frac{R}{\rho^{(d i r)}}\right)} \exp \left(-\frac{z}{\zeta_{e c h}^{(d i r)}}\right) .
$$

Next, the direct radiation energy flux, encountering the front side of a full chamber (denoted by the subscript $f(h)$, is expressible as

$$
\dot{Q}_{f c h}^{(d i r)}(r, 0)=a_{s}^{(d i r)} A_{f c h} I \cos \theta, \quad \forall r \in\{0, R\}
$$

Then, the flux penetrating the material $(z \geq 0)$ is

$$
\dot{Q}_{f c h}^{(d i r)}(r, z)=a_{f c h}^{(d i r)} \dot{Q}_{f c h}^{(d i r)}(r, 0)=a_{s}^{(d i r)} a_{f c h}^{(d i r)} A_{f c h} I \cos (\theta), \quad \forall r \in[0, R]
$$

with the damping function

$$
a_{f c h}^{(d i r)}=\exp \left(-\frac{z}{\rho^{(d i r)}}\right)
$$

which contains the same bulk penetration length $\rho^{(\mathrm{dir})}$ as introduced in Eq. (3.1/24).

The $z$-component of the desired heat flux density vector is obtained by dividing the term in Eq. (3.1/30b) by the surface area $A_{f c h}$

$$
\dot{q}_{z}^{(d i r)}(z)=a_{s}^{(d i r)} \exp \left(-\frac{z}{\rho^{(d i r)}}\right) I \cos (\theta)
$$

\subsection{Absorption of diffuse solar radiation}

The diffuse radiation entering a full chamber in the radial direction is obtained by averaging in Eq. (3.1/28) over all the occurring incident angles $\theta$, by changing $I$ to $D$ (see below) and the superscript from (dir) to (dif). This process yields 
$\dot{q}_{r}^{(d i f)}(r, z)=-\frac{1}{2 \pi^{2}} \frac{n A_{e c h} D}{\zeta_{e c h}^{(d i f)}} \frac{1}{r} \frac{\cosh \left(\frac{r}{\rho^{(d i f)}}\right)}{\cosh \left(\frac{R}{\rho^{(d i f)}}\right)} \int_{-\frac{\pi}{2}}^{\frac{\pi}{2}} e^{-\log _{e}\left(r_{s}^{(d i f)}\right) \frac{z}{d} \tan \theta} \cos (\theta) d \theta$,

where in the integrand in Eq. (3.1/20b) was substituted, and $D$ denotes the energy flux density of diffuse radiation.

In analogy to $(3.1 / 30)$ the absorption of diffuse radiation at and behind the left boundary of a filled chamber is

$\dot{Q}_{f c h}^{(d i f)}(r, z)=a_{f c h}^{(d i f)} \dot{Q}_{f c h}^{(d i f)}(r, 0)=a_{s}^{(d i f)} a_{f c h}^{(d i f)} A_{f c h} D, \quad \forall r \in[0, R]$,

with

$a_{f c h}^{(d i f)}=\exp \left(-\frac{z}{\rho^{(d i f)}}\right)$.

By a division with the cross-section area of a full chamber $A_{\text {fch, }}$ one obtains the heat flux density component

$\dot{q}_{z}^{(d i f)}(z)=a_{s}^{(d i f)} \exp \left(-\frac{z}{\rho^{(d i f)}}\right) D$.

\subsection{Absorption of the global solar radiation}

The volumetric absorbed energy is obtained by the divergence of the heat flux density, for axisymmetric processes,

$\dot{q}_{\text {Source }}=\operatorname{div}\left(\dot{\vec{q}}_{\text {Rad }}\right)=\frac{1}{r} \frac{\partial\left[r\left(\dot{q}_{r}^{(d i r)}+\dot{q}_{r}^{(d i f)}\right)\right]}{\partial r}+\frac{\partial\left[\dot{q}_{z}^{(d i r)}+\dot{q}_{z}^{(d i f)}\right]}{\partial z}$.

Introducing the terms given by Eq. (3.1/28), (3.1/32) for the direct radiation and those in Eq. (3.2/1) and (3.2/4) for the diffuse radiation, it follows that

$\dot{q}_{\text {Source }}=-\left[\frac{n A_{\text {ech }}}{2 \pi r \zeta_{\text {ech }}^{(d i r)} \rho^{(d i r)}} \frac{\sinh \left(\frac{r}{\rho^{(d i r)}}\right)}{\cosh \left(\frac{R}{\rho^{(d i r)}}\right)} \exp \left(-\frac{z}{\zeta_{\text {ech }}^{(d i r)}}\right)+\frac{a_{s}^{(d i r)}}{\rho^{(d i r)}} \exp \left(-\frac{z}{\rho^{(d i r)}}\right)\right] I \cos (\theta)-$ 


$$
\left[\frac{n A_{e c h}}{2 \pi^{2} r \zeta_{e c h}^{(d i f)} \rho^{(d i f)}} \frac{\sinh \left(\frac{r}{\rho^{(d i f)}}\right)}{\cosh \left(\frac{R}{\rho^{(d i f)}}\right)} \int_{-\frac{\pi}{2}}^{\frac{\pi}{2}} \exp \left(\log _{e}\left(r_{s}^{(d i f)}\right) \frac{z}{\bar{d}} \tan \theta\right) \cos (\theta) d \theta+\frac{a_{s}^{(d i f)}}{\rho^{(d i f)}} \exp \left(-\frac{z}{\rho^{(d i f)}}\right)\right] D .
$$

\subsection{Energy conservation in the PCM storage device}

The physical modeling of the PCM is performed by the application of the ContinuousProperties Model (CPM) developed by Egolf and Manz (1994).

Neglecting convective terms in the internal energy balance and also ignoring possible stress powers, the energy conservation law can be written as

$$
\frac{\partial q}{\partial t}+\operatorname{div}\left(\dot{\vec{q}}_{D i f}\right)-\operatorname{div}\left(\dot{\vec{q}}_{\text {Source }}\right)=0
$$

where $\partial q$ in terms of the specific enthalpy $h$ and Fourier's law for the diffusion process $\operatorname{div}\left(\overrightarrow{\dot{q}}_{D i f}\right)$, are expressed as

$$
\partial q=\rho \partial h, \quad \overrightarrow{\dot{q}}_{D i f}=-k \vec{\nabla} T,
$$

so that Eq. (3.4/1) takes the form

$$
\rho \frac{\partial h}{\partial t}-\operatorname{div}(k \vec{\nabla} T)-\operatorname{div}\left(\dot{\vec{q}}_{\text {Source }}\right)=0
$$

From this, there follows, because a description of PCM behavior strictly requires $h=h(T)$ and $k=k(T)$

$$
\rho \frac{d h}{d T} \frac{\partial T}{\partial t}-k \Delta T-\frac{d k}{d T}(\vec{\nabla} T \cdot \vec{\nabla} T)-\operatorname{div}\left(\dot{\vec{q}}_{\text {Source }}\right)=0
$$

With the effective specific heat capacity, $c_{p}(T)$, and the effective thermal diffusivity, $\alpha(T)$

$$
c_{p}=\frac{d h(T)}{d T}, \quad \alpha(T)=\frac{k(T)}{\rho c_{p}(T)}, \quad \rho=\frac{\rho_{\text {sol }}+\rho_{l i q}}{2} \cong \text { const }
$$

Then, by dividing Eq. (3.4/4) by $\rho$ and $c_{p}$, with the help of Eq. (3.4/5b) and abbreviating $\dot{q}_{\text {Source }}$ by $\dot{q}_{S o}$, one obtains the main differential equation with a heat source term describing the solar energy absorption: $\dot{q}_{\text {Source }}=\dot{q}_{\text {So }}$, 


$$
\frac{\partial T}{\partial t}-\alpha\left\{\Delta T+\frac{1}{k}\left[\frac{d k}{d T}(\vec{\nabla} T \cdot \vec{\nabla} T)-\operatorname{div}\left(\dot{\vec{q}}_{S o}\right)\right]\right\}=0
$$

An economic manner to write the two-dimensional nonlinear diffusion equation for the three basic geometric PCM bodies (plates, spheres and cylinders) is (see Egolf et al., 1997c)

$$
\frac{\partial T}{\partial t}-\alpha\left\langle\frac{\partial^{2} T}{\partial x_{1}^{2}}+c_{1} \frac{\partial^{2} T}{\partial x_{2}^{2}}+\frac{c_{2}}{x_{1}} \frac{\partial T}{\partial x_{1}}+\frac{1}{k}\left\{\frac{d k}{d T}\left[\left(\frac{\partial T}{\partial x_{1}}\right)^{2}+c_{3}\left(\frac{\partial T}{\partial x_{2}}\right)^{2}\right]-\frac{\partial \dot{q}_{S o, 1}}{\partial x_{1}}-\frac{1}{x_{2} c_{2}} \frac{\partial\left(x_{2}^{c_{2}} \dot{q}_{S o, 2}\right)}{\partial x_{2}}\right\}\right\rangle=0
$$

with the following constants for spatially two-dimensional problems (see Egolf et al., 1997c)

$$
\begin{array}{lll}
\text { Plates : } & c_{1}=1, \quad c_{2}=0, \quad c_{3}=1, \\
\text { Spheres : } & c_{1}=0, \quad c_{2}=2, \quad c_{3}=0, \\
\text { Cylinders : } & c_{1}=1, \quad c_{2}=1, \quad c_{3}=1,
\end{array}
$$

where in this article only the last line, with the characteristic values for cylinders, is applied.

Here, the simplest geometrical situation will be studied, namely that of circular channels, which are in the total azimuthal direction of $360^{\circ}$ surrounded by empty channels (see Figure 1 on the left-hand side). This is the situation of a cylindrical melting/freezing problem. If the structure is of polygonal shape of higher order, e.g. equal to six (number of edges), a cylinder, with an equivalent diameter leading to the same volume, may be taken as an approximation for the polygon (see FIG. 1 on the left-hand side (circle in the left top corner)). However, in this case, the heat transfer area is different and a correction must be made. Higher filling degrees lead to other configurations of higher complexity. The structure of FIG. 1, on the right-hand side, can also be roughly approximated, namely by a concentric cylindrical domain. For more accuracy or in other more complex situations the spatial dimension must be chosen to be three. We only study the spatial two-dimensional cylindrical case.

For the cylindrical case, changing the denotation of the variables by $x_{l}=r$ and $x_{2}=z$, we find

$$
\frac{\partial T}{\partial t}-\alpha\left\langle\frac{\partial^{2} T}{\partial r^{2}}+\frac{1}{r} \frac{\partial T}{\partial r}+\frac{\partial^{2} T}{\partial z^{2}}+\frac{1}{k}\left\{\frac{d k}{d T}\left[\left(\frac{\partial T}{\partial r}\right)^{2}+\left(\frac{\partial T}{\partial z}\right)^{2}\right]-\frac{\partial}{\partial z} \dot{q}_{S o, z}-\frac{1}{r} \frac{\partial}{\partial r}\left(r \dot{q}_{S o, r}\right)\right\}\right\rangle=0
$$

The source term is given by Eq. (3.3/2).

\subsection{Initial and boundary conditions for cylindrical PCM elements}

The initial condition is that in the PCM all temperatures are the same 
$T(t=0, r, z)=T_{0}, \quad \forall r \in[0, R], \quad \forall z \in[0, L]$,

with, for example, $T_{0}=293.16 \mathrm{~K}\left(20^{\circ} \mathrm{C}\right)$.

The boundary condition for the front side is given by

$\frac{\partial T}{\partial z} \mid(t, r, 0)=\frac{B i_{z}}{L}\left[T(t, r, 0)-T_{f}(t, 0)\right], \quad \forall r \in[0, R], \quad B i_{z}=\frac{\tilde{h} L}{k}$,

with the Biot number $B i_{z}$ for the $z$-direction. Analogously, one defines for the back side

$$
\frac{\partial T}{\partial z} \mid(t, r, L)=\frac{B i_{z}}{L}\left[T_{f}(t, L)-T(t, r, L)\right], \quad \forall r \in[0, R] .
$$

The symmetry axis in the centre of the cylinder is the location of the condition describing a vanishing radial heat flux and thereby also directional derivative, viz.,

$$
\frac{\partial T}{\partial r} \mid(t, 0, z)=0, \quad \forall z \in[0, L]
$$

The heat flux at the side walls of the cylinder must obey a further and last boundary condition

$$
\frac{\partial T}{\partial r} \mid(t, R, z)=\frac{B i_{r}}{R}\left[T_{f}(t, z)-T(t, R, z)\right], \quad \forall z \in[0, L], \quad B i_{r}=\frac{\tilde{h} R}{k},
$$

with the Biot number $B i_{r}$ for the radial direction. In the continuous model the boundary conditions $(3.5 / 2 \mathrm{a}, \mathrm{b})$ and $(3.5 / 5 \mathrm{a}, \mathrm{b})$ are complete. However, when a discretization is performed the front corner element experiences two heat fluxes arriving and two leaving. This means that one heat flux is coming in and one is leaving in horizontal direction. For the corner element, a combination of these four heat fluxes must be taken into consideration. This is developed by considering the following energy conservation equation,

$$
\dot{q}_{r, \text { in }}+\dot{q}_{r, \text { out }}+\dot{q}_{z, \text { in }}+\dot{q}_{z, \text { out }}=0 .
$$

In the material parts these heat fluxes are fluxes given by diffusion and on the other side they are defined by heat transfer. Expressed with finite differences these considerations lead to

$$
-k \frac{T(t, R-\Delta r, 0)-T(t, R, 0)}{\Delta r}-k \frac{T(t, R, \Delta z)-T(t, R, 0)}{\Delta z}+2 \tilde{h}\left[T(t, R, 0)-T_{f}(0)\right]=0,
$$

in which $T_{f}$ is the temperature of the fluid. The last expression can be rearranged to become 
$T(t, R-\Delta r, 0)-T(t, R, 0)+\frac{\Delta r}{\Delta z}[T(t, R, \Delta z)-T(t, R, 0)]=2 \frac{\Delta r}{R} B i_{r}\left[T(t, R, 0)-T_{f}(0)\right]$.

Solving this for the temperature in the corner element leads to

$$
T(t, R, 0)=\frac{T(t, R-\Delta r, 0)+\frac{\Delta r}{\Delta z} T(t, R, \Delta z)+2 \frac{\Delta r}{R} B i_{r} T_{f}(0)}{1+\frac{\Delta r}{\Delta z}\left(1+2 B i_{r}\right)} .
$$

In analogy, one obtains for the other corner at the back side, where now the following signs of the increments are valid

$$
T(t, R, L)=\frac{T(t, R-\Delta r, L)+\frac{\Delta r}{\Delta z} T(t, R, L-\Delta z)+2 \frac{\Delta r}{R} B i_{r} T_{f}(L)}{1+\frac{\Delta r}{\Delta z}\left(1+2 B i_{r}\right)} .
$$

All the physical quantities $\chi$ of the PCM are modeled by exponential functions as outlined in Egolf and Manz (1994). For these quantities, the main parameters are the value of the solid $\chi_{\text {sol }}$ and the liquid phase $\chi_{\text {liq. }}$ Furthermore, important are the melting temperature of the PCM, $T_{m}$, and the width of the transition region (mushy zone), characterized by the temperature difference $\tau$ (for its definition see in Egolf and Manz, 1994). The exponential functions continuously (and analytically) approximate the transition between the solid and liquid phase, which is assumed to show identical widths for all the physical properties. This leads to high numerical stability and low computation (CPU) time. The numerical values (simulation parameters) are given in Table 1.

\subsection{Initial condition of the fluid and determination of the downstream fluid temperature}

The theory presented up-to-here describes the solar charging of the PCM storage device and the diffusion and phase transition phenomena in the PCM. However, additionally, the "empty" channels allow a crossing of the storage device by a heat transfer fluid, which usually is air. This can lead to an additional charging, but by counter action can also be used for a discharging of the thermal storage device. Such convective flows also occur in these new storage modules as part of a ventilation or an air-conditioning system. Decentralized façade air-conditioning systems can favorably be equipped by the proposed new storage module. The convective heat transport by a fluid is the topic of this subchapter.

The initial condition for the fluid is, e.g.

$T_{f}(t=0, z)=T_{f 0}, \quad \forall z \in[0, L]$. 
Starting point to determine the fluid temperature as a function of time $t$ and downstream direction $z$ is the energy equation of a Eulerian fluid, neglecting diffusion in the fluid, pressure related energy, viscous dissipation energy, energy produced by external forces, etc.,

$\rho \frac{D e}{D t}+\operatorname{div}\left(\dot{\vec{q}}_{h e x}\right)=0$

where the index hex denotes heat exchange or with the substantial derivative in more detail

$$
\frac{\partial e}{\partial t}+w \frac{\partial e}{\partial z}+\frac{1}{\rho} \operatorname{div}\left(\dot{\vec{q}}_{h e x}\right)=0 .
$$

Because the small thermal inertia of the fluid (air) is negligible, it follows that

$$
w \frac{\partial e}{\partial z}=-\frac{1}{\rho} \operatorname{div}\left(\dot{\vec{q}}_{h e x}\right)
$$

Now, we integrate over an empty channel domain $\Gamma$, containing fluid and showing the boundary surface $\partial \Gamma$. This yields

$$
\int_{\Gamma} w \frac{\partial e}{\partial z} d V=-\frac{1}{\rho} \int_{\Gamma} \operatorname{div}\left(\dot{\vec{q}}_{h e x}\right) d V
$$

The density exhibits small variation, so that the velocity and density can be assumed to be constant. Now, the divergence theorem is applied to (3.6/5) and an integration over an infinitesimal slice in the $z$-direction is performed, which yields

$$
A_{e c h} w \int_{\delta \Gamma} \frac{\partial e}{\partial z} d z=-\frac{1}{\rho} \int_{\partial \delta \Gamma} \dot{\vec{q}}_{h e x} d \vec{A}=-\frac{1}{\rho} \int_{\partial \delta \Gamma} \dot{\vec{q}}_{h e x} \vec{n} d A
$$

where $\vec{n}$ is the exterior unit normal vector on $\partial \Gamma$.

In differential form this can be written as

$$
\rho w A_{e c h} \partial e=\dot{m} \partial e=\partial \dot{Q}_{h e x},
$$

with

$\partial e=c_{p f} \partial T_{f}$

and 
$\partial \dot{Q}_{h e x}(z)=2 \pi R \tilde{h}\left[T(t, R, z)-T_{f}(z)\right] \partial z$,

where $\tilde{h}$ denotes the heat transfer coefficient at the surface of the empty cells. Eqs. (3.6/7) with (3.6/8) and (3.6/9) imply

$\rho w A_{e c h} c_{p f} \partial T_{f}(z)=2 \pi R \tilde{h}\left[T(t, R, z)-T_{f}(z)\right] \partial z$,

respectively with $A_{\text {ech }}=\pi R^{2}$,

$\frac{\partial T_{f}(t, z)}{\partial z}=\frac{2}{R} S t\left[T(t, R, z)-T_{f}(z)\right], \quad S t=\frac{\tilde{h}}{\rho w c_{p f}}, \quad z \in[0, L]$,

where $S t$ denotes the dimensionless Stanton number.

The system has quantities that are responsible for its forcing or driving, namely one geometrical quantity and three physical quantities, explicitly

$\theta, I, D, T_{f}(t, 0)$.

The state of the storage device is described by the specific enthalpy or temperature

$h(T(t, r, z)) \quad$ or $\quad T(t, r, z)$,

at each time and location in the PCM, because the continuous equation of state, $h(T)$, defines a continuous and monotonically increasing relation between enthalpy density and temperature. The energy contained in the entire storage module is

$H(t)=\int_{\Gamma} h(T(t, r, z)) d V(r, z)$,

where the zero-state enthalpy $H=0$ can be arbitrarily chosen. Here the volume is related just to the domain of the ensemble of filled chambers. If one wishes to refer to the total domain, a package degree must be defined.

The following equations are required to solve the above initial boundary value problem problem: The basic equation Eq. (3.4/9) with its source term (3.3/2) and the initial conditions (3.5/1) and (3.6/1). Furthermore, the boundary conditions are Eq. (3.5/2a,b) up to Eq. $(3.5 / 5 \mathrm{a}, \mathrm{b})$ and $(3.6 / 11 \mathrm{a}, \mathrm{b})$. The state of the storage is defined by (3.6/14) and the forcing of the system is given by Eq. (3.6/12a-d). Mathematically the ensemble of these equations define a well-posed parabolic initial boundary value problem that was numerically solved by Amacker (2011). 


\section{NUMERICAL SIMULATION RESULTS}

\subsection{Charging by direct and diffuse light absorption}

The main phenomenon is the charging of the honeycomb/PCM module with direct and diffuse solar radiation. An example is shown in FIG. 7. The small cylindrical containers are filled with a PCM showing a homogeneous temperature field of $20^{\circ} \mathrm{C}$. At $t=0$ absorption of direct and diffuse radiation starts. The incident angle $\theta$ of direct radiation is $17.8^{\circ}$. Now, the PCM slowly heats up and the first results show the spatial temperature distribution after 0.8 hours (a). The further results are always displayed after another 0.8 hours and are shown in the figures b) to f). The parameters of the numerical simulations are listed in Table 1. Furthermore, one finds in the appendix also the (empirical) formulas for the heat transfer coefficients of laminar and turbulent flow through the channels of the honeycomb structure, where, depending on the Reynolds number, the valid relation was chosen.

The solar radiation arrives from the left and encounters the left front surface. Furthermore, some radiation enters the empty channels adjacent to the filled cylinders and this leads to a further absorption of solar energy at the surface of filled cylinders in the interior of these channels. Because this absorption is exponentially decreasing downstream, the ring-shaped corner is the region which absorbs most solar energy and heats up with the largest heating rate. In the cross section of the cylinder this shows up on the left-hand side in the lower and higher corner regions. In this example, solar radiation continuously heats the cylinder and, because there are no losses, and neither convective heat transfer processes, the heating procedure would go on to an infinitely high temperature.

\subsection{Discharging by convective heat transfer}

Another mode is the charging and discharging of the storage device by convective heat transfer. Because charging such modules is usually performed by solar radiation and only discharging occurs by convective heat transfer, here a discharging mode is presented. In FIG. 8 six cross sections of a PCM cylindrical container of $2 \mathrm{~cm}$ diameter and $10 \mathrm{~cm}$ length are shown. The PCM is assumed to be in thermal equilibrium with a homogenous initial temperature of $30{ }^{\circ} \mathrm{C}$ (a). After an hour, the PCM enters the mushy transition region, with a mean melting temperature of $22{ }^{\circ} \mathrm{C}(\mathrm{b})$, and after one hour and a half the warm core has become smaller in the center domain (c). A thicker core region downstream as compared to more upstream occurs, because the fluid in the downstream direction obtains heat from the PCM module. By this the temperature difference between the border of the PCM and the fluid, with increasing temperature, decreases and, therefore, less heat is transferred. Finally caused by this, downstream the heat exchange is smaller, leading to less solidification. After two hours, the PCM has left the transition region and the core becomes more circular (d). It is interesting to see that in this stage the elliptic figure becomes broader than long (e). After two and a half hours, with good accuracy, the PCM shows a homogenous temperature field again, but now with the temperature of the cold fluid, which in this case is $5{ }^{\circ} \mathrm{C}$. 


\subsection{Charging by light absorption and discharging by convective heat transfer}

In this third case charging and discharging, as shown in the last two subsections, are now occurring simultaneously. One sees that the PCM, after being initially again at $20{ }^{\circ} \mathrm{C}$ (see FIG. 9a), slightly heats up at the left side by solar energy absorption (FIGs. 9b-e). On the right, where the heat source is less effective, the cooling dominates and the temperature is lower. After 2.4 hours, the PCM approximately reaches its spatial steady state temperature distribution, where the absorbed solar radiation and the heat transported away by heat transfer and fluid convection are in equilibrium (see FIG. 9f).
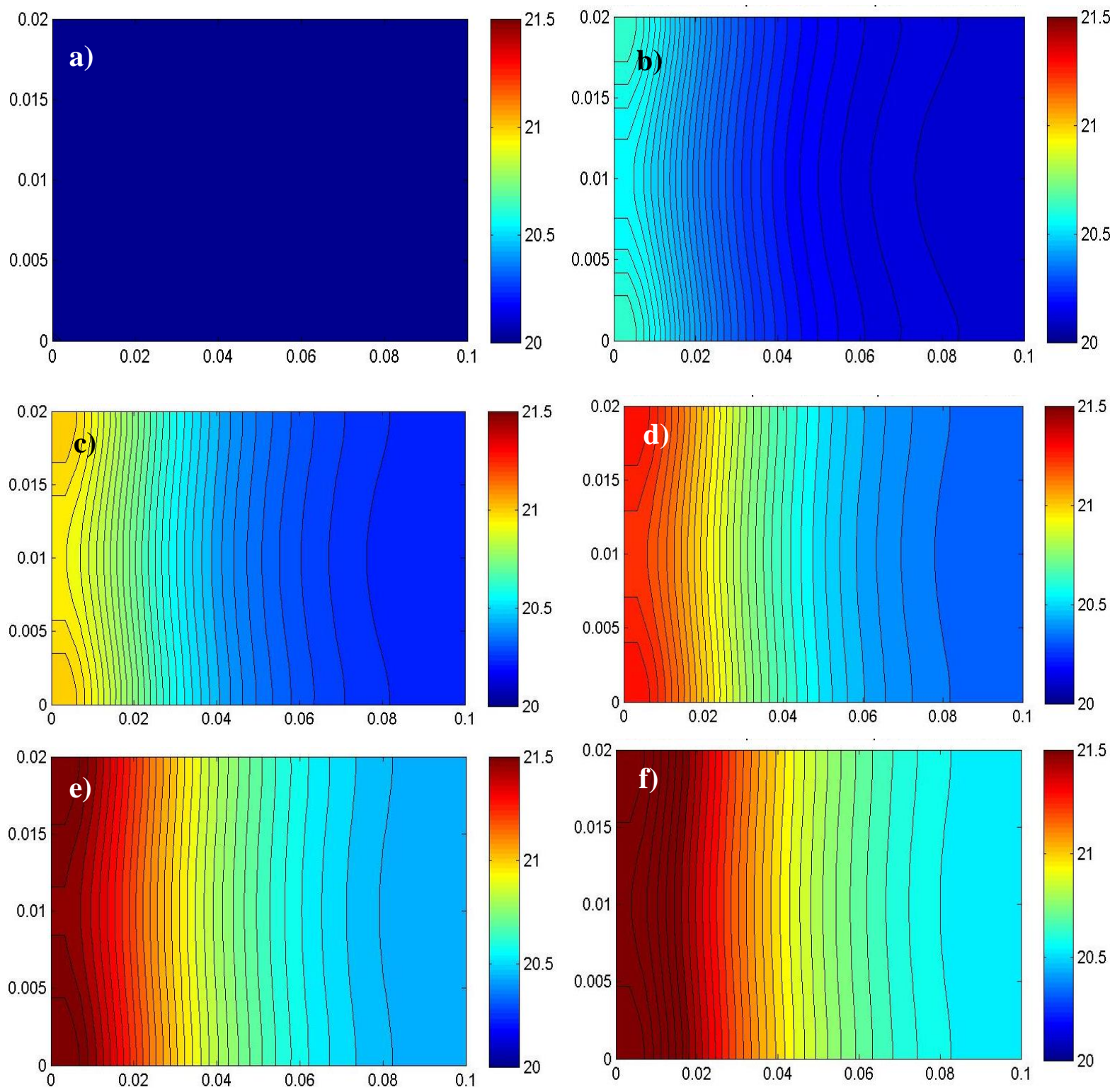

Fig. 7. Six states of a cross section of a cylindrical PCM module are shown at $t=0 \mathrm{~h}$ (a), $0.8 \mathrm{~h}$ (b), $1.6 \mathrm{~h} \mathrm{(c),} 2.4 \mathrm{~h}(\mathrm{c}), 3.2 \mathrm{~h}(\mathrm{~d})$ and $4 \mathrm{~h}(\mathrm{f})$. The initial temperature of this charging mode is uniformly at $20{ }^{\circ} \mathrm{C}$. Then, the storage element starts to continuously heat up. The abszissa values are the $z$-coordinates in meter and the ordinate values the $r^{*}$-coordinates with a spatial translation obeying $r^{*}=r+0.01$, with the unit also being 'meter'. Therefore, the axis of the cylinder is found at $r=0$ or $r^{*}=0.01$, respectively. 

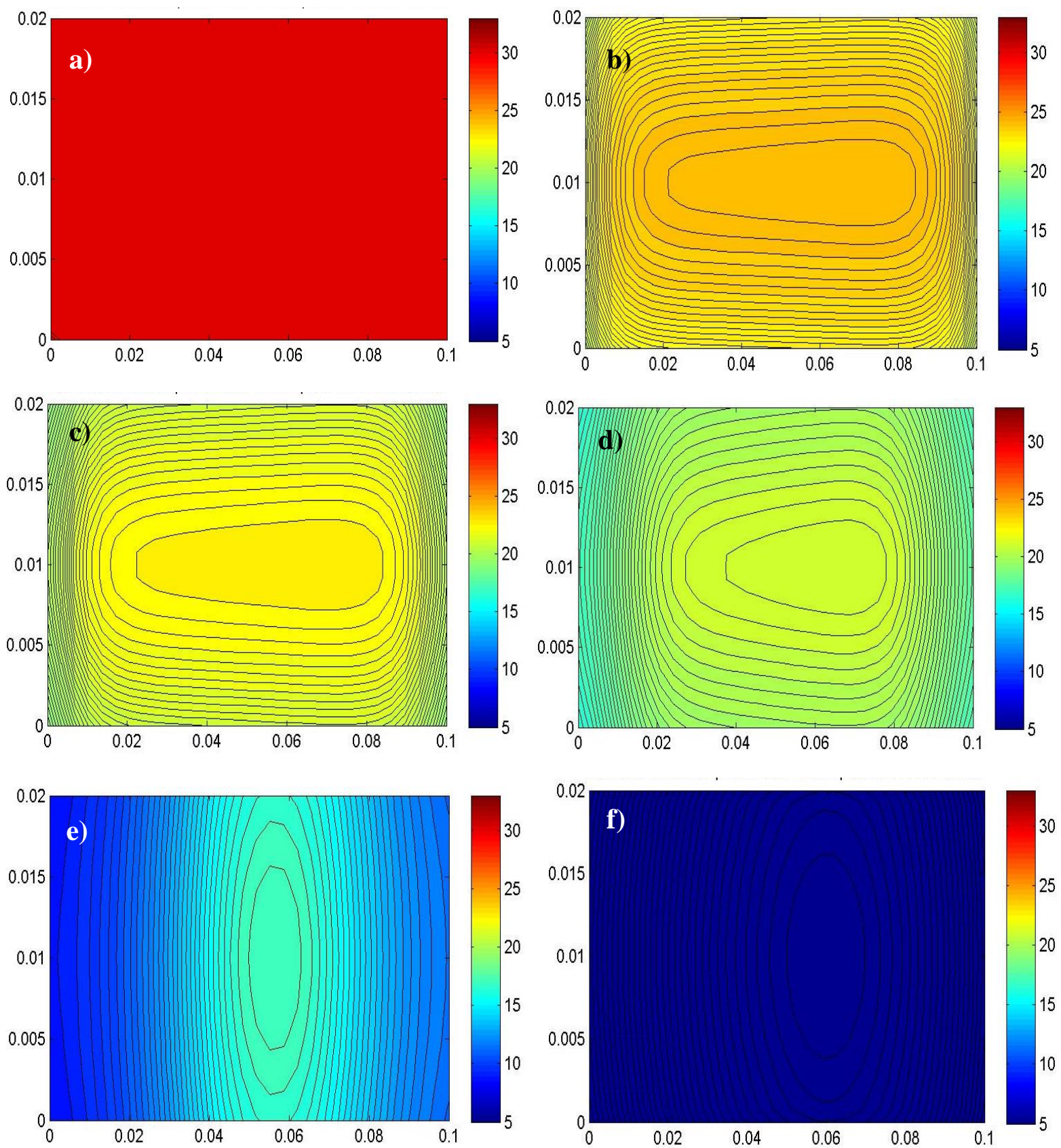

Fig. 8. Six states of a cross section of a cylindrical PCM module, shown at $t=0 \mathrm{~h}$ (a), $1 / 2 \mathrm{~h}$ (b), $1 \mathrm{~h} \mathrm{(c),} 11 / 2 \mathrm{~h} \mathrm{(d),2} \mathrm{h}(\mathrm{e})$ and $21 / 2 \mathrm{~h}(\mathrm{f})$. The initial temperature of this discharging mode is $30{ }^{\circ} \mathrm{C}$ and the final one $5{ }^{\circ} \mathrm{C}$. The abszissa values are the $z$-coordinates in meter and the ordinate values the $r^{*}$-coordinates with a spatial translation obeying $r^{*}=r+0.01$, with the unit also being 'meter'. Therefore, the axis of the cylinder is found at $r=0$ or $r^{*}=0.01$, respectively. 

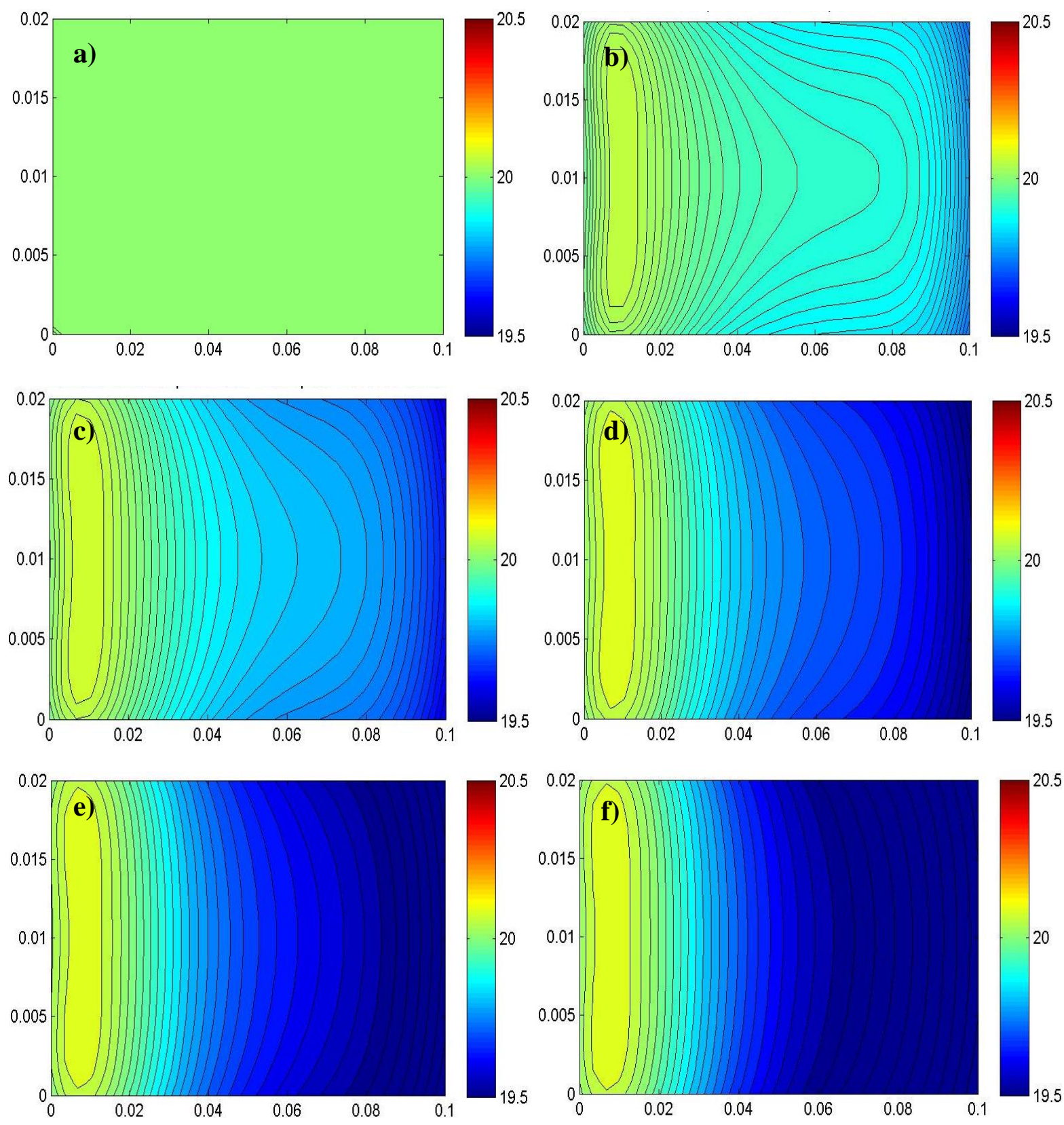

Fig. 9. Six states of a cross section of a cylindrical PCM module, shown at $t=0 \mathrm{~h}$ (a), $0.5 \mathrm{~h}$ (b), $1 \mathrm{~h}(\mathrm{c}), 1.5 \mathrm{~h}(\mathrm{~d}), 2 \mathrm{~h}(\mathrm{e})$ and $2.5 \mathrm{~h}$ (f). The initial temperature of this charging and discharging mode is $20{ }^{\circ} \mathrm{C}$. The storage element arrives in a steady state after approximately 2.4 hours. The abszissa values are the $z$-coordinates in meter and the ordinate values the $r^{*}$-coordinates with a spatial translation obeying $r^{*}=r+0.01$, with the unit also being 'meter'. Therefore, the axis of the cylinder is found at $r=0$ or $r^{*}=0.01$, respectively. 
Table 1. Parameters of the numerical simulations.

\begin{tabular}{|c|c|c|}
\hline Symbol & Value & Unit \\
\hline$c p_{a i r}$, specific heat capacity of air & 1000 & $\mathrm{~J} \mathrm{~kg}^{-1} \mathrm{~K}^{-1}$ \\
\hline$c p_{\text {solid, }}$, specific heat capacity of PCM, solid phase & 1400 & $\mathrm{~J} \mathrm{~kg}^{-1} \mathrm{~K}^{-1}$ \\
\hline$c p_{\text {liquid, }}$, specific heat capacity of PCM, liquid phase & 2200 & $\mathrm{~J} \mathrm{~kg}^{-1} \mathrm{~K}^{-1}$ \\
\hline$D$, diameter of cylinders & 0.02 & $\mathrm{~m}$ \\
\hline$D$, density of diffuse radiation & 200 & $\mathrm{~W} \mathrm{~m}^{-2}$ \\
\hline Deltat, time step & 1 & $\mathrm{~s}$ \\
\hline$I$, density of direct radiation & 740 & $\mathrm{~W} \mathrm{m^{-2 }}$ \\
\hline$k_{\text {liquid, }}$ thermal conductivity of PCM, liquid phase & 0.54 & 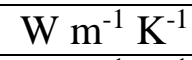 \\
\hline$k_{\text {solid, }}$ thermal conductivity of PCM, solid phase & 1.09 & 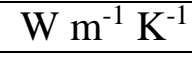 \\
\hline$L$, length of honeycomb module & 0.1 & $\mathrm{~m}$ \\
\hline$m$, number of time steps & variable & - \\
\hline$n$, number of increments in $r$-direction plus one & 8 & - \\
\hline$o$, number of increments in $z$-direction plus one & 15 & - \\
\hline$h$, melting enthalpy & $192 ’ 000$ & $\mathrm{~J} \mathrm{~kg}^{-1}$ \\
\hline$r^{(d i r)}$, coefficient of reflection, direct radiation & 0.6 & - \\
\hline$r^{(d i f)}$, coefficient of reflection, diffuse radiation & 0.6 & - \\
\hline$R$, radius of cylinder & 0.01 & $\mathrm{~m}$ \\
\hline$\tau$, width of mushy region & 2 & $\mathrm{~K}$ \\
\hline$T_{m}$, mean melting temperature of PCM & 22 & ${ }^{\circ} \mathrm{C}$ \\
\hline$T_{0}$, initial temperature of PCM & 20,30 & ${ }^{\circ} \mathrm{C}$ \\
\hline$T_{f o}$, initial fluid temperature & 5 & ${ }^{\circ} \mathrm{C}$ \\
\hline$V$, volumetric mass flow per filled cylinder & 3.0 & $\mathrm{~m}^{3} \mathrm{~h}^{-1}$ \\
\hline$\theta$, incident angle of solar rays & 17.8 & $\circ$ \\
\hline$\rho^{(d i r)}$, absorption coefficient, direct radiation & 0.003 & $\mathrm{~m}$ \\
\hline$\rho^{(d i f)}$, absorption coefficient, diffuse radiation & 0.003 & $\mathrm{~m}$ \\
\hline$\rho$, density of PCM & 1800 & $\mathrm{~kg} \mathrm{~m}^{-3}$ \\
\hline$\rho_{\text {air }}$, density of air & 1,293 & $\mathrm{~kg} \mathrm{~m}^{-3}$ \\
\hline
\end{tabular}

\section{APPENDIX}

The empirical formulas for the heat transfer applied are the following (see Incropera et al., 2006):

Laminar flow $(\operatorname{Re} \leq 2300)$ :

$$
N u=\frac{\tilde{h} L}{k}=3.66+\frac{0.0688\left(\frac{d}{L}\right) \operatorname{Re} \operatorname{Pr}}{1+0.04\left[\left(\frac{d}{L}\right) \operatorname{Re} \operatorname{Pr}\right]^{2 / 3}} .
$$


Turbulent flow $(\operatorname{Re} \geq 2300)$ :

$N u=0.023 \operatorname{Re}^{4 / 5} \operatorname{Pr}^{1 / 3}$

Please note that no calculations for the transition region of the flow were performed. The calculations in this work were performed with Eq. (A/2) for turbulent flow.

\section{CONCLUSIONS}

A new translucent honeycomb solar energy collecting and storing module was designed. In this article this module is described in detail and scientific results of its performance are presented. It is a successor of translucent solar energy systems, following other inventions, as e.g. one with transparent insulation and glass blocks filled with a PCM of Manz et al., 1997 or the system of Weinläder et al. 2005, a similar system where glass windows, instead of transparent insulation, are applied.

In the context of an EU project (see acknowledgements) accurate physical models have been developed and are now presented in this article.

Our solar radiation recursive absorption model is based on several simplifications. For example, the varying step sizes of the solar rays into the empty channels between two absorption processes is replaced by a weight- averaged step distance. Furthermore, because the main part of the incident rays rotates in the channel, we have assumed that the absorption distribution is azimuthally symmetric, which is only approximately valid. In the end, generalizations of this method lead to much higher complexity with a small gain of higher precision; such is left for future investigation.

The absorption model of the transparent insulation part is used as source term in the CPM of Egolf and Manz, 1994; it describes melting/freezing in the PCM-filled horizontal channels as a nonlinear diffusion process. Isoline plots of temperature fields of a charging mode by solar energy absorption, a discharging mode by heat transfer and fluid convection, and a third case, which is the superposition of the latter two, leading to a steady state solution, are presented.

The charging by direct and diffuse solar radiation of this façade module makes it to be an excellent candidate for passive, active and hybrid solar (building façade) systems. It also could have numerous ideal applications as a component in decentralized air-conditioning systems, e.g. applying heat recovery apparatuses (Noume, 2010; Egolf et al., 2014, 2015).

We are in discussion involved to test and validate this new solar energy system in a laboratory with an artificial light source, developed and investigated by Courret et al., 2011 and 2017. The new sulphur light source shows a light spectrum very close to that of the sun (and human eye sensitivity) and by this favors a controlled testing of outdoor solar energy equipment in indoor laboratories. 
A further step is to figure out different building applications, as it was already partly performed in the Master thesis of Noume (2010). Then, also these applications should be numerically optimized and tested in laboratory set-ups.

\section{ACKNOWLEDGEMENTS}

This work was performed under the umbrella of the EU COST ACTION TU 0802 (Next generation cost effective phase change materials for increased energy efficiency in renewable energy systems in buildings (NeCoE-PCM)). We are grateful to Sarah McCormack and Robert Weber for their support. Arsene Noumes prize-winning Master thesis was performed in a collaboration with the Polytechnical University of Torino, Italy; we are grateful to Marco Masoero. The work in this article was performed in memoriam of Frederik Setterwall (KTH Stockholm, Sweden), the first authors former mentor concerning the PCM technology.

\section{NOMENCLATURE}

\begin{tabular}{|c|c|c|}
\hline Symbol & & Unity \\
\hline \multicolumn{3}{|l|}{ Standard } \\
\hline$a$ & Absorption coefficient & - \\
\hline$A$ & Area & $\mathrm{m}^{2}$ \\
\hline$c$ & Specific heat capacity & $\mathrm{J} \mathrm{kg}^{-1} \mathrm{~K}^{-1}$ \\
\hline$d$ & (Equivalent) diameter & $\mathrm{m}$ \\
\hline $\bar{d}$ & Averaged (equivalent diameter) & $\mathrm{m}$ \\
\hline$D$ & Diameter of cylinder & $\mathrm{m}$ \\
\hline$D$ & Energy flux density of diffuse radiation & $\mathrm{W} \mathrm{m}^{-2}$ \\
\hline Deltat & Time step & $\mathrm{s}$ \\
\hline$e$ & Internal energy & $\mathrm{J} \mathrm{m}^{-3}$ \\
\hline$h$ & Specific enthalpy & $\mathrm{J} \mathrm{kg}^{-1}$ \\
\hline$\tilde{h}$ & Heat transfer coefficient & $\mathrm{Wm}^{-2} \mathrm{~K}^{-1}$ \\
\hline$H$ & Enthalpy & $\mathbf{J}$ \\
\hline$I$ & Energy flux density of direct radiation & $\mathrm{W} \mathrm{m}^{-2}$ \\
\hline$k$ & Thermal conductivity & 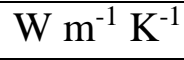 \\
\hline$l$ & Distance between two neighboring reflections & $\mathrm{m}$ \\
\hline $\bar{l}$ & Averaged distance between neighboring reflections & \\
\hline$L$ & Length of module & $\mathrm{m}$ \\
\hline$n_{k}$ & Order of polygon (number of kinks) & - \\
\hline$n_{r}$ & Number of rotations & - \\
\hline$n$ & Ratio of empty and full chambers & - \\
\hline$\vec{n}$ & Normal vector building facade & - \\
\hline$N$ & Number of reflections & - \\
\hline
\end{tabular}




\begin{tabular}{|c|c|c|}
\hline $\bar{N}$ & Averaged number of reflections & - \\
\hline$q$ & Volumetric energy & $\mathrm{J} \mathrm{m}^{-3}$ \\
\hline$\dot{q}$ & Specific heat flux & $\mathrm{W} \mathrm{m}^{-2}$ \\
\hline$\dot{Q}$ & Heat flux & W \\
\hline$r$ & Radial coordinate & $\mathrm{m}$ \\
\hline$r$ & Coefficient of reflection & - \\
\hline$R$ & Radius of cylinder & $\mathrm{m}$ \\
\hline$t$ & time & $\mathrm{s}$ \\
\hline$V$ & Volume & $\mathrm{m}^{3}$ \\
\hline$w$ & Velocity & $\mathrm{m} \mathrm{s}^{-1}$ \\
\hline$z$ & Downstream coordinate & $\mathrm{m}$ \\
\hline \multicolumn{3}{|c|}{$\begin{array}{l}\text { Nondimensional } \\
\text { numbers }\end{array}$} \\
\hline$B i$ & Biot number & - \\
\hline $\mathrm{Nu}$ & Nusselt number & - \\
\hline $\mathrm{Pr}$ & Prandtl number & - \\
\hline $\operatorname{Re}$ & Reynolds number & - \\
\hline St & Stanton number & - \\
\hline \multicolumn{3}{|c|}{ Greek } \\
\hline$\alpha$ & Diffusion coefficient & $\mathrm{m}^{2} \mathrm{~s}^{-1}$ \\
\hline$\chi$ & Symbol for auxiliary quantity & - \\
\hline$\Gamma$ & Domain & - \\
\hline$\partial \Gamma$ & Surface of domain & - \\
\hline$\theta$ & Angle of direct incident solar rays & o \\
\hline$\rho$ & Density & $\mathrm{kg} \mathrm{m}^{-3}$ \\
\hline$\rho$ & Penetration depth in radial direction & $\mathrm{m}$ \\
\hline$\Omega$ & Ratio of heat fluxes & - \\
\hline$\zeta$ & Penetration depth in downstream direction & $\mathrm{m}$ \\
\hline \multicolumn{3}{|c|}{ Indices } \\
\hline air & Air & - \\
\hline$b$ & Bulk & - \\
\hline dif & Diffuse & - \\
\hline Dif & Diffusion & - \\
\hline dir & Direct & - \\
\hline ech & Empty chamber & - \\
\hline$f$ & Fluid & - \\
\hline$f c h$ & Filled chamber (PCM containing chamber) & - \\
\hline hex & Heat exchange & - \\
\hline
\end{tabular}




\begin{tabular}{|l|l|l|}
\hline in & Entering, inlet & - \\
\hline$k$ & Index, spatial $z$-coordinate & - \\
\hline liquid & Liquid & - \\
\hline$m$ & Melting & \\
\hline out & Exit, outlet & - \\
\hline$r$ & Radial & - \\
\hline$S$ & Surface & - \\
\hline solid & solid & - \\
\hline Source & Source term & \\
\hline$z$ & downstream & - \\
\hline
\end{tabular}

\section{REFERENCES}

Amacker, N., 2011. Système solaire d'air conditionné en façade se basant sur des matériaux à changement de phase. Diploma work performed at the University of Applied Sciences of Western Switzerland, Institute of Thermal Sciences and Engineering, Yverdon-lesBains, Switzerland, supervision by Peter W. Egolf and Gregory Gottschalk.

Auracher, H., Egolf, P.W., (Ed.'s) 2006. Special Issue on Magnetic Refrigeration at Room Temperature. Int. J. Refr. 29 (8).

Balocco, C., Forastière, M.A., Grazzini, G., Righini, G.C., 2001. Experimental results of transparent, reflective and absorbing properties of some building materials. Energy and Building, 33, 563-568.

Bouhssine, Z., Najam, M., El Alami, M., 2016. Phase change material for solar thermal energy storage in buildings: Numerical study, J. Sol. Energy Eng. 138 (6): 061006-061006-8.

Butala, V., Stritih, U., 2006. Cold storage with phase change material for building ventilation. Int. J. Vent. 5 (2), 189-198.

Cabeza, L. F., Castellón, C., Nogués, M., Medrano, M., Leppers, R., Zubillaga, O., 2007. Use of micro-encapsulated PCM in concrete walls for energy savings. Energy and Buildings 39, 113-119.

Courret, G., Pawlowski, A.-G., Croci, M., 2011. Tests de la nouvelle alimentation et exploration du comportement du plasma en modulation pulsée. Final report of Hesso project No. 23761 (in French).

Courret, G., Nikkola, P., Wasterlain, S., Gudozhnik, O., Girardin, M., Braun, J., Gavin, S., Carpita, M., Croci, M., Egolf, P.W., 2017. On the plasma confinement by acoustic resonance. Euro Phys. J. D 71, 214-238.

Egolf, P.W., Manz, H., 1994. Theory and modeling of phase change materials with and without mushy regions. Int. J. Heat Mass Transfer, 37 (18), 2917-2924.

Egolf, P.W., Manz, H., Furter, R., Odermatt, A., Frei, B., Lüscher, H., 1994. The Continuousproperties Model and Colour-visualized Experiments of a Water Storage Tank Containing Spherical PCM Capsules. Proceedings of the Sixth International Conference on Thermal Energy Storage, 22-25 August, Helsinki University of Technology, Espoo, Finland, Volume 2, 495-502. 
Egolf, P.W., Frei, B., Furter, R., 1997a. A Simplified Model to describe Heat Transfer by Free Convection in a Water Storage Tank containing Spherical Phase Change Material Capsules. Megastock'97, Seventh International Conference on Thermal Energy Storage, Sapporo, Japan, June 18-21, Volume 1, 145-150.

Egolf, P.W., Frei, B., Furter, R., 1997b. Konvektion im Wasserraum von Latentwärmespeichern. CISBT'97, Conférence Internationale Energie Solaire et Bâtiment, École Polytechnique Fédéral de Lausanne, Laboratoire d'Energie Solaire et de Physique du Bâtiment, 1-2 Octobre, 317-326 (in German).

Egolf, P.W., Koschenz, M., Lehmann, B., 1997c. Latentwärmespeicher für die Sonnenenergienutzung: Lade- und Entladevorgänge. Schlussbericht des Forschungsprojektes Nr. 515 zuhanden des Nationalen Energie-Forschungs-Fonds (NEFF), 1- 73 (in German).

Egolf, P.W., Kauffeld, M., 2005. From physical properties of ice slurries to industrial ice slurry applications, Special Issue on Ice Slurrries, Int. J. Refr. 28, 4-12.

Egolf, P.W., Rosensweig, R.E., 2007. Magnetic Refrigeration at Room Temperature. $20^{\text {th }}$ Informatory Note on Refrigeration Technologies of the International Institute of Refrigeration, Paris, October, 1-8.

Egolf, P.W., Noume, A.N., Vuarnoz, D., Gottschalk, G., 2014. Breathing Building: A decentralized façade-integrated solar air-conditioning system. International Special Issue of the United Nations Environmental Program, UNEP, the International Institute of Refrigeration, IIF-IIR, and the Italian Ministry of the Environment, 58-61.

Egolf, P.W., Noume, A.N., Vuarnoz, D., Gottschalk, G., 2015."Edificio traspirante”: Sistema d'aria condizionata decentrato con facciata solare integrato. Speciale nuove tecnologie. Industria \& Formazione, 385, 40-43 (in Italian).

Fanger, P.O., 2007, Thermal comfort: Analysis and applications in environmental engineering. Danish Technical Press, University of Michigan, ISBN 9788757103410.

Feustel, H.E., Stetiu, C., 1997. Thermal Performance of Phase Change Wallboard for Residential Cooling Application. Report LBL-38320, UC-1600, Lawrence Berkeley National Laboratory, University of California, USA.

Grynning, St., Goia, F., Rognvik, E., Time, B., 2013. Possibilities for characterization of a PCM window system using large-scale measurements, Int. J. Sustain. Built Env. 2 (1), 56-64.

Hadjieva, M., Gutzow, I., Vassilev, T., 2003. Phase Change Structured Fluids for Thermal Energy Storage: Tetradekane Case Study. Phase Change Material \& Slurry: Engineering Conference \& Business Forum, Yverdon-les-Bains, Switzerland, 23-26 April, 27-32.

Hauer, A., Mehling, H., Schossig, P., Yamaha, M., Cabeza, L., Martin, V., 2005. Annex 17: Advanced Thermal Energy Storage Through Phase Change Materials and Chemical Reactions-Feasibility Studies and Demonstration Projects. International Energy Agency Implementing Agreement on Energy Conservation Through Energy Storage.

Hausmann, T., Schossig, P., 2006. Baustoffe mit Phasenwechselmaterialien als Kältespeicher für energieffiziente Gebäude. Statusseminar "Thermische Energiespeicherung - mehr Energie zum Heizen und Kühlen", Freiburg, 2.-3. November (in German).

He, B., Gustafsson, E.M., Setterwall, F., 1999. Tetradecane and hexadecane binary mixtures as phase change materials (PCM) for cool storage in district cooling systems. Energy 24, 1015-1028.

Heinz, A., Streicher, W., 2005. Experimental Testing of a Storage Tank Filled with Microencapsulated PCM Slurries. Proceedings of the Second Conference on Phase Change Ma- 
terial \& Slurry, Scientific Conference and Business Forum, Yverdon-les-Bains, Switzerland, 15-17 June.

Incropera, F.P., Dewitt, D.P., Bergman, Th. L., Lavine, A.S., 2007. Fundamentals of Heat and Mass Transfer, John Wiley \& Sons, Hoboken, USA, ISBN 13-978-0-471-45728-2.

Ismail, K.A.R., Salinas, C.T., Henriquez, J.R., 2008. Comparison between PCM filled glass windows and absorbing gas filled windows. Energy and Buildings 40, 710-719.

Kauffeld, M., Kawaji, M., Egolf, P.W., 2005. Handbook on Ice Slurries- Fundamentals and Engineering. International Institute of Refrigeration, IIF/IIR Paris.

Kenisarin, M., Mahkamov, K., 2007. Solar energy storage using phase change materials, Renewable and Sustainable Energy Reviews, 11, 1913-1965.

Kudhair, A.M., Farid, M.M., 2004. A review on energy conservation in building applications with thermal energy storage by latent heat using phase change materials. Energy Conversion Management 45 (2), 263-275.

Kuznik, F., Damine, D., Kevyn, J., Roux, J.-J., 2011, A review on phase change materials integrated in building walls, Renew. and Sustain. Energy Rev. 15 (1), 379-391.

Lane, G.A., 1983. Solar Heat Storage: Latent Heat Material - Background and Physical Principles, Volume I, CRC Press Florida.

Lehmann, B., Weber, R., Hadorn, J.-Ch., 2005. Thermal Storage in Building Structures: Thermally Activated Building Systems (TABS). In Handbook of Task 32 of the International Energy Agency: Thermal Energy Storage for Solar and Low Energy Building, Ed. J.-Ch. Hadorn.

Liu, S., Hao, L., Guo, X., Rao, Z., 2015. Experimental study on crystallization process and freezing properties of ice slurry generation based sodium chloride solution, Energy Procedia 75, 1445-1451.

Manz, H., Egolf, P.W., Suter, P., Goetzberger, A., 1997. TIM-PCM external wall system for solar space heating and daylighting. Solar Energy, 61 (6), 369-379.

Manz, H., 2003. Numerical simulation of heat transfer by natural convection in cavities of façade elements. Energy and Buildings, 35, 305-311.

Martin, V., He, B., Setterwall, F., 2010. Direct-contact PCM-water cold storage. Applied Energy, 87, 2652-2659.

Mehling, H., Cabeza, L., 2008. Heat and Cold Storage with PCM, Springer Verlag, Berlin, ISBN: 9783540685562.

Noume, A.N., 2010. Breathing Building: A New Façade Air-conditioning System. Master thesis of the University of Torino and University of Applied Sciences of Western Switzerland, Yverdon-les-Bains,Switzerland, Supervisors: M. Masoero, P.W. Egolf, 1-98.

Platzer, J. W., 1987. Solar transmission of transparent insulation material. Solar Energy Materials, 16, 275-287.

Platzer, J.W., 1992. Directional-hemispheric solar transmittance data for plastic honeycombtype structures, Solar Energy, 49 (5), 359-370.

Schwarz, D., Nussbaumer, Th., 2002. Eine Wand die schmilzt (A wall that melts). Tec21, 24, 7- 13 (in German).

Sharma, S.D., Sagara, K., 2005. Latent heat storage materials and systems: A review. Int. J. Green Energy, 2, 1-56.

Sinha Ray, S., Sahu, R.P., Yarin, A.L., 2011. Nano-encapsulated smart tunable phase change Materials. Soft Matter, 7, 8823-8828. 
Takeda, S., Nagano, K., Mochida, T., Nakamura, T., 2003. Development of Floor Supply Air Conditioning System with Granulated Phase Change Materials. Proceedings of Futurestock, Ninth International Conference on Thermal Energy Storage, Warsaw, Poland, 1.-4. September.

Telkes, M., 1949. Review of solar house heating. Heat Vent. 46 (9), 68-74.

Wang, X., Zhang, L., Yu, Y.-H., Jia, L., Mannan, M.S., Chen, Y., Cheng, Z., 2015. Nanoencapsulated PCM via Pickering Emulsification. Sci. Rep. 5, 13357, DOI: 10.1038/srep 13357.

Weinläder, H., Beck, A., Fricke, J., 2005. PCM-façade-panel for daylighting and room heating. Sol. Energy, 78 (2), 177-186.

Wong, I.L., Eames, P.C., Perera, R.S., 2007. A review of transparent insulation systems and the evaluation of payback period for building applications. Solar Energy 81, 1058-1071.

Zhang, Y., Zhou, G., Lin, K., Zhang, Q., Di, H., 2007. Application of latent heat thermal energy storage in buildings: State-of-the-art and outlook. Building and Environment 42, 2197-2209.

Zhu, N., Ma, Z., Wang, S. 2009. Dynamic characteristics and energy performance of buildings using phase change materials: A review. Energy Conversion and Management, 50, 3169-3181. 